\section{OPEN ACCESS}

Edited by:

Tatsuo Shioda,

Osaka University, Japan

Reviewed by:

Newman Osafo,

Kwame Nkrumah University of Science and Technology, Ghana

Aman Babanrao Upaganlawar,

Shri Neminath Jain

Brahmacharyashram, India

*Correspondence:

Md. Sahab Uddin

msu-neuropharma@hotmail.com; msu_neuropharma@hotmail.com

tORCID:

Md. Sahab Uddin orcid.org/0000-0002-0805-7840

Specialty section:

This article was submitted to

Molecular Medicine,

a section of the journal

Frontiers in Cell and Developmental

Biology

Received: 03 May 2020

Accepted: 22 June 2020

Published: 10 July 2020

Citation:

Kabir MT, Uddin MS, Hossain MF, Abdulhakim JA, Alam MA, Ashraf GM,

Bungau SG, Bin-Jumah MN,

Abdel-Daim MM and Aleya L (2020)

nCOVID-19 Pandemic: From

Molecular Pathogenesis to Potential Investigational Therapeutics.

Front. Cell Dev. Biol. 8:616.

doi: 10.3389/fcell.2020.00616

\title{
nCOVID-19 Pandemic: From Molecular Pathogenesis to Potential Investigational Therapeutics
}

Md. Tanvir Kabir ${ }^{1}$, Md. Sahab Uddin ${ }^{2,3 *+}$, Md. Farhad Hossain ${ }^{3,4}$, Jawaher A. Abdulhakim ${ }^{5}$ Md. Asraful Alam ${ }^{6}$, Ghulam Md Ashraf ${ }^{7,8}$, Simona G. Bungau ${ }^{9}$, May N. Bin-Jumah ${ }^{10}$, Mohamed M. Abdel-Daim ${ }^{11,12}$ and Lotfi Aleya ${ }^{13}$

\begin{abstract}
1 Department of Pharmacy, Brac University, Dhaka, Bangladesh, ${ }^{2}$ Department of Pharmacy, Southeast University, Dhaka, Bangladesh, ${ }^{3}$ Pharmakon Neuroscience Research Network, Dhaka, Bangladesh, ${ }^{4}$ Department of Physical Therapy, Graduate School of Inje University, Gimhae, South Korea, ${ }^{5}$ Department of Medical Laboratory, Faculty of Applied Medical Sciences, Taibah University, Yanbu, Saudi Arabia, ${ }^{6}$ School of Chemical Engineering, Zhengzhou University, Zhengzhou, China, ${ }^{7}$ King Fahd Medical Research Center, King Abdulaziz University, Jeddah, Saudi Arabia, ${ }^{8}$ Department of Medical Laboratory Technology, Faculty of Applied Medical Sciences, King Abdulaziz University, Jeddah, Saudi Arabia, ${ }^{9}$ Department of Pharmacy, Faculty of Medicine and Pharmacy, University of Oradea, Oradea, Romania, ${ }^{10}$ Department of Biology, College of Science, Princess Nourah Bint Abdulrahman University, Riyadh, Saudi Arabia, ${ }^{11}$ Department of Zoology, College of Science, King Saud University, Riyadh, Saudi Arabia, ${ }^{12}$ Pharmacology Department, Faculty of Veterinary Medicine, Suez Canal University, Ismailia, Egypt, ${ }^{13}$ Chrono-Environnement Laboratory, UMR CNRS 6249, Bourgogne Franche-Comté University, Besançon, France
\end{abstract}

In December 2019, a severe acute respiratory syndrome coronavirus 2 (SARS-CoV-2)-related epidemic was first observed in Wuhan, China. In 2020, owing to the highly infectious and deadly nature of the virus, this widespread novel coronavirus disease 2019 (nCOVID-19) became a worldwide pandemic. Studies have revealed that various environmental factors including temperature, humidity, and air pollution may also affect the transmission pattern of COVID-19. Unfortunately, still, there is no specific drug that has been validated in large-scale studies to treat patients with confirmed nCOVID-19. However, remdesivir, an inhibitor of RNA-dependent RNA polymerase (RdRp), has appeared as an auspicious antiviral drug. Currently, a large-scale study on remdesivir (i.e., $200 \mathrm{mg}$ on first day, then $100 \mathrm{mg}$ once/day) is ongoing to evaluate its clinical efficacy to treat nCOVID-19. Good antiviral activity against SARS-CoV-2 was not observed with the use of lopinavir/ritonavir (LPV/r). Nonetheless, the combination of umifenovir and LPV/r was found to have better antiviral activity. Furthermore, a combination of hydroxychloroquine (i.e., $200 \mathrm{mg} 3$ times/day) and azithromycin (i.e., $500 \mathrm{mg}$ on first day, then $250 \mathrm{mg} /$ day from day 2-5) also exhibited good activity. Currently, there are also ongoing studies to evaluate the efficacy of teicoplanin and monoclonal and polyclonal antibodies against SARS-CoV-2. Thus, in this article, we have analyzed the genetic diversity and molecular pathogenesis of nCOVID-19. We also present possible therapeutic options for nCOVID-19 patients.

Keywords: SARS-CoV-2, nCOVID-19, RdRp inhibitors, remdesivir, favipiravir, immunomodulators, corticosteroids, eculizumab 


\section{INTRODUCTION}

Coronaviruses (CoVs) belong to the large family of positivesense, enveloped, highly diverse, and single-stranded RNA viruses (Fehr and Perlman, 2015). Indeed, CoVs have been found to infect both humans and animals, therefore causing various respiratory, gastrointestinal, neuronal, and hepatic diseases (Weiss and Leibowitz, 2011; Chan et al., 2013; Zumla et al., 2016). Former epidemics of $\mathrm{CoVs}$ include severe acute respiratory syndrome (SARS)-CoV and Middle East respiratory syndrome (MERS)-CoV, these outbreaks caused severe health problems in humans (Raoult et al., 2020). A group of individuals was admitted to hospitals in late December of 2019 with a primary diagnosis of pneumonia due to an unknown cause (Bogoch et al., 2020; Lu et al., 2020). It was assumed by the earlier reports that the onset of a potential $\mathrm{CoV}$ epidemic provided the estimation of a reproduction number for the 2019 novel coronavirus (nCOVID19, named by World Health Organization (WHO) on Feb 11, 2020) which was thought to be considerably $>1$ (ranges from 2.24-3.58) (Zhao et al., 2020).

This severe acute respiratory syndrome coronavirus 2 (SARS$\mathrm{CoV}-2$ ) can be transmitted largely via droplets and due to the close contact. It has been found that elderly people and individuals with chronic diseases or comorbidities are particularly high-risk populations (Li et al., 2020a). There are various symptoms of nCOVID-19 including cough (68\%), fever (88\%), diarrhea (3.7\%), and vomiting (5\%) (Mungroo et al., 2020). The mode of transmission of SARSCoV-2 is supposed to take place from human to human through respiratory secretions released by the infected people when sneezing and coughing (Mungroo et al., 2020). nCOVID-19 patients can be asymptomatic, which is making the control of the transmission more difficult (Gao et al., 2020; Li et al., 2020a). Since February of 2020, strict infection control approaches were executed by the Centers for Disease Control (CDC) in order to limit the spread of SARS-CoV-2. In a recent study, To et al. (2020) mentioned that nCOVID-19 patients had the highest viral load (measured in saliva samples) near presentation. They also summarized that as viral load is quite high during the time of hospital admissions, use of potent antiviral agents at an early stage might prove

Abbreviations: ACE2, angiotensin converting enzyme 2; AP, antigen presentation; APCs, antigen presentation cells; APN, aminopeptidase N, ARBs, angiotensin II receptor blockers; ARDS, acute respiratory distress syndrome; CDC, Centers for Disease Control; nCOVID-19, novel coronavirus disease 2019; CoVs, coronaviruses; DPP4, dipeptidyl peptidase 4; dsRNA, double-strand RNA; $\mathrm{EC}_{50}$, half maximal effective concentration; ED, emergency department; ELISA, enzymelinked immunosorbent assay; EUA, emergency use authorization; FDA, Food and Drug Administration; GGO, ground-glass opacity; HCV, hepatitis C virus; HIV, human immunodeficiency virus;, MHC, major histocompatibility complex; or HLA, human leukocyte antigen; ICU, intensive care unit; IL-6, interleukin 6; LPV/r, lopinavir/ritonavir; mAbs, monoclonal antibodies; MERS, Middle East respiratory syndrome; N7-MTase, N7-methyltransferase; NSAIDs, nonsteroidal anti-inflammatory drugs; PRRs, pattern recognition receptors; PUI, patient under investigation; RdRp, RNA-dependent RNA polymerase; RSV, respiratory syncytial virus; S protein, spike protein; SAM, S-adenosyl-methionine; SARS, severe acute respiratory syndrome; SARS-CoV-2, Severe acute respiratory syndrome coronavirus 2; TMPRSS2, transmembrane serine protease 2; WHO, World Health Organization. beneficial in managing the severity of nCOVID-19 infection (To et al., 2020).

Previously, SARS was found to be partially linked with environmental factors (Lin et al., 2006). In a study, it was revealed that air pollution was linked with mortality in SARS patients in China (Cui et al., 2003). In this regard, it was mentioned that lung functions can be compromised owing to long- or shortterm exposure to certain environmental pollutants (Cui et al., 2003). Air temperature is another factor that is also needed to be considered. It has been revealed by Lin et al. (2006) that the occurrence of SARS was much higher (18 times) at lower air temperatures as compared to higher temperatures. Researchers also showed that respiratory disorders are more likely to take place in colder environments since virulence of agents are likely to deteriorate at higher air temperatures because they might not endure the alterations in the environment (D'Amato et al., 2018). In addition to this, they also summarized that SARSCoV's transmissibility is comparable with the transmissibility of influenza virus. Moreover, the occurrence of influenza markedly elevates with high relative humidity and low temperatures (Park et al., 2020), which is further suggesting that viral transmission can be significantly affected by environmental factors.

There are no therapeutic agents that have been approved to treat nCOVID-19. Various medicines including immunomodulatory or antiviral drugs such as remdesivir, favipiravir, ribavirin, chloroquine, hydroxychloroquine, azithromycin, nitazoxanide, teicoplanin etc. have been advised as potential investigational drugs, many of which are now being studied in animals and humans (Wang et al., 2020b; WHO, 2020c). On March 28, 2020, the Food and Drug Administration (FDA) gave an emergency use authorization (EUA) for emergency use of oral administrations of chloroquine phosphate and hydroxychloroquine sulfate to treat SARS-CoV-2 infection (FDA, 2020). Along with oxygen and mechanical ventilation, a guideline has also been published by Belgium which involved recommendations from four other European countries, including Switzerland, Netherlands, France, and Italy that recommended the use of remdesivir, lopinavir/ritonavir, tocilizumab, and chloroquine or hydroxychloroquine (Sciensano, 2020). In addition, Japan and China approved the use of favipiravir (an antiviral agent) to treat influenza, which is now under investigation to treat nCOVID-19 (Fujifilm, 2020).

In this article, we have critically appraised the genetic diversity, molecular pathogenesis, symptoms, diagnosis, and prevention of nCOVID-19. Furthermore, we also specially reviewed the mechanisms, efficacy, and use of various drugs that might be beneficial in combating nCOVID-19 infection.

\section{GENETIC DIVERSITY AND EVOLUTION OF nCOVID-19}

In nature, nucleotide substitution is considered as a vital step for viral evolution (Lauring and Andino, 2010). The rapid spreading of SARS-CoV-2 raised a suspicion that mutations are driving its evolution. In a recent study, from GISAID, Phan (2020a) collected 86 complete or near-complete SARS-CoV-2 genomes 
TABLE 1 | Several missense mutations have been identified in the entire genome of nCOVID-19 strains (Phan, 2020a).

\begin{tabular}{|c|c|c|c|c|}
\hline Location & $\begin{array}{l}\text { Number of } \\
\text { mutations }\end{array}$ & Codon & Mutation & Region(s) of strain(s) \\
\hline \multirow[t]{2}{*}{ Matrix protein } & 2 & & 1 & \\
\hline & & 209 & Asp $\rightarrow$ His & Singapore \\
\hline 3'UTR & 3 & & $\mathrm{~N} / \mathrm{A}$ & \\
\hline Intergenic region & 5 & & $\mathrm{~N} / \mathrm{A}$ & \\
\hline Intergenic region & 6 & & $\mathrm{~N} / \mathrm{A}$ & \\
\hline \multirow{5}{*}{$\begin{array}{l}\text { Nucleocapsid } \\
\text { protein }\end{array}$} & 7 & & 4 & \\
\hline & & 148 & Thr $\rightarrow$ Ile & China (Shenzhen) \\
\hline & & 194 & Ile $\rightarrow$ Leu & $\begin{array}{l}\text { China (Shenzhen) China } \\
\text { (Foshan) USA USA }\end{array}$ \\
\hline & & 202 & Ser $\rightarrow$ Asn & Australia \\
\hline & & 344 & Pro $\rightarrow$ Ser & Hong Kong (Guangzhou) \\
\hline 5' UTR & 8 & & N/A & \\
\hline \multirow{9}{*}{$\begin{array}{l}\text { Spike } \\
\text { polyprotein }\end{array}$} & 14 & & 8 & \\
\hline & & 32 & Phe $\rightarrow$ Ile & China (Wuhan) \\
\hline & & 49 & $\mathrm{His} \rightarrow \mathrm{Tyr}$ & China (Guangdong) \\
\hline & & 247 & Ser $\rightarrow$ Arg & Australia \\
\hline & & 354 & Asn $\rightarrow$ Asp & China (Shenzhen) \\
\hline & & 364 & Asp $\rightarrow$ Tyr & China (Shenzhen) \\
\hline & & 367 & Val $\rightarrow$ Phe & France \\
\hline & & 614 & Asp $\rightarrow$ Gly & Germany \\
\hline & & 1143 & Pro $\rightarrow$ Leu & Australia \\
\hline \multirow{25}{*}{$\begin{array}{l}\text { ORF1ab } \\
\text { polyprotein }\end{array}$} & 48 & & 29 & \\
\hline & & 117 & Ala $\rightarrow$ Thr & USA \\
\hline & & 309 & Pro $\rightarrow$ Ser & France \\
\hline & & 428 & Ser $\rightarrow$ Asn & USA \\
\hline & & 609 & Thr $\rightarrow$ Ile & USA \\
\hline & & 1176 & $\mathrm{Ala} \rightarrow \mathrm{Val}$ & Japan \\
\hline & & 1599 & Leu $\rightarrow$ Phe & Korea \\
\hline & & 1607 & $\| l e \rightarrow$ Val & USA \\
\hline & & 2194 & Met $\rightarrow$ Thr & China (Shenzhen) \\
\hline & & 2235 & Leu $\rightarrow$ Ile & China (Wuhan) \\
\hline & & 2244 & $\| \mathrm{e} \rightarrow \mathrm{Thr}$ & China (Wuhan) \\
\hline & & 2251 & Gly $\rightarrow$ Ser & China (Wuhan) \\
\hline & & 2345 & $\mathrm{Ala} \rightarrow \mathrm{Val}$ & China (Shandong) \\
\hline & & 2534 & Gly $\rightarrow$ Val & China (Wuhan) \\
\hline & & 2579 & Asp $\rightarrow$ Ala & China (Wuhan) \\
\hline & & 2708 & Asn $\rightarrow$ Ser & China (Wuhan) \\
\hline & & 2908 & Phe $\rightarrow$ lle & China (Wuhan) \\
\hline & & 3058 & Thr $\rightarrow$ Ile & France \\
\hline & & 3099 & Ser $\rightarrow$ Leu & China (Shenzhen) \\
\hline & & 3606 & Leu $\rightarrow$ Phe & $\begin{array}{l}\text { China (Yunnan) China } \\
\text { (Shandong) China } \\
\text { (Chongqing) Singapore } \\
\text { France USA }\end{array}$ \\
\hline & & 3764 & Glu $\rightarrow$ Asp & Japan \\
\hline & & 3833 & Asn $\rightarrow$ Lys & China (Wuhan) \\
\hline & & 5308 & Trp $\rightarrow$ Cys & Taiwan \\
\hline & & 5579 & $\mathrm{Thr} \rightarrow$ Ile & USA \\
\hline & & 6075 & $\| \mathrm{e} \rightarrow \mathrm{Thr}$ & England \\
\hline
\end{tabular}

(Continued)
TABLE 1 | Continued

\begin{tabular}{llll}
\hline Location & $\begin{array}{c}\text { Number of } \\
\text { mutations }\end{array}$ & Codon Mutation & Region(s) of strain(s) \\
\hline & 6083 Pro $\rightarrow$ Leu & Japan \\
$6309 \quad$ Phe $\rightarrow$ Tyr & China (Sichuan) \\
$6565 \quad$ Glu $\rightarrow$ Asp & China (Shenzhen) \\
$6958 \quad$ Lys $\rightarrow$ Arg & China (Wuhan) \\
$7018 \quad$ Asp $\rightarrow$ Asn & China (Wuhan)
\end{tabular}

to estimate its genetic variation. In addition to this, these strains of SARS-CoV-2 were identified in patients with confirmed nCOVID-19 from USA (11), China (50), Japan (5), Australia (5), England (2), Singapore (3), France (4), Germany (1), Belgium (1), South Korea (1), Vietnam (1), and Taiwan (2). ClustalX2 was used to align the pair-wise nucleotide sequence (Saitou and Nei, 1987). As a reference genome, the sequence of the strain "China/WHU01/2020/EPI_ISL_406716" was used. Interestingly, similar to other beta coronaviruses, the genome of SARS-CoV-2 contains a long ORF1ab polyprotein at the $5^{\prime}$ end, followed by 4 main structural proteins, such as nucleocapsid protein, matrix protein, small envelope protein, and spike surface glycoprotein (Phan, 2020b). In addition to this, it was also observed that there were 3 deletions in the genomes of SARS-CoV-2 from Australia (Victoria), USA (Wisconsin), and Japan (Aichi). In contrast, 1 deletion (10 nucleotides) was found in the $3^{\prime}$ end of the genome, while 2 deletions ( 2 nucleotides and 24 nucleotides) were found in the ORF1ab polyprotein.

Furthermore, it was also observed from the nucleotide sequence alignment that there were 93 missense mutations in the entire genomes of novel coronavirus (Table 1). Except for the envelope protein, 42 mutations were detected in all of the main structural and non-structural proteins. Whereas, 4 missense mutations were observed in the nucleocapsid protein, 1 in the matrix protein, 29 in the ORFlab polyprotein, and 8 in the spike surface glycoprotein. Interestingly 3 mutations (i.e., $\mathrm{Phe}^{367}, \mathrm{Tyr}^{364}$, and $\mathrm{Asp}^{354}$ ) were found in the spike surface glycoprotein receptor-binding domain. Indeed, spike surface glycoprotein contributes significantly in binding to receptors on the host cell and eventually regulates host tropism (Fung and Liu, 2019). Furthermore, this spike glycoprotein is the main target of neutralizing antibodies (Yu et al., 2020). Conformational changes of spike glycoprotein can be induced by the mutations, which can lead to altered antigenicity. Up until now, no study has identified the amino acids that are involved in conformational alterations of spike glycoprotein. Therefore, further studies are required to identify these important amino acids.

\section{TRANSMISSION PATTERN OF nCOVID-19 AND ENVIRONMENTAL FACTORS}

Various wild and domestic animals such as bats, cats, cattle, and camels might play a role as hosts for coronaviruses (Adhikari et al., 2020). In general, animal coronaviruses do not spread 
among human beings (CDC, 2020a). Nevertheless, exceptions have been noticed in case of MERS and SARS, where these diseases were found to be transmitted owing to the contact with respiratory droplets from sneezing or coughing of nCOVID-19 patients. Initial nCOVID-19 patients were detected in China, where there was an association with the seafood market of Wuhan, which is indicating that these initial infections took place because of the animal-to-person transmission. Later on, nCOVID-19 was also detected in healthcare professionals and also in other individuals where there was no history of contact with that affected area of Wuhan, which is further suggesting the human-to-human transmission (Gralinski and Menachery, 2020; Huang et al., 2020; Li et al., 2020b; Liu et al., 2020; WHO, 2020d).

As per the recent guidelines from health authorities of China (Adhikari et al., 2020; WHO, 2020e), there are 3 major routes of nCOVID-19 transmission including droplets transmission, aerosol transmission, and contact transmission. Transmissions via droplets were found to take place when respiratory droplets of infected individuals are inhaled or ingested by people who are in close contact. Whereas, contact transmission might take place when a person touches a virus-contaminated-object or surface and then that person touches his/her nose, mouth, or eyes. On the other hand, aerosol transmission might take place when respiratory droplets mix into the air, thus forms aerosols and might result in infection when a high dose of aerosols are inhaled into the lungs in a comparatively closed environment (Adhikari et al., 2020; WHO, 2020e). In a study, it was revealed that the digestive system is also a possible route for SARS-CoV-2 transmission. Symptoms like diarrhea and abdominal discomfort have been observed in individuals with confirmed nCOVID-19, this observation led to studies which revealed that ACE2 (to which SARS-CoV-2 binds) is highly expressed in enterocytes of colon and ileum (Zhang et al., 2020b).

\section{Temperature}

The effect of temperature on the health of humans can be varied depending on the countries or even areas (Hajat and Kosatky, 2010). In line with this aforesaid finding, it was also reported that temperature can affect the transmission of respiratory syndromes-causing viruses including SARS-CoV-2 (Ma et al., 2020) and influenza virus (Park et al., 2020). Studies have also revealed that novel coronavirus and influenza virus can survive only in some specific environmental conditions and their transmissions also depend on temperatures (Chan et al., 2011; Jaakkola et al., 2014), which is also applicable for SARSCoV-2 transmission (Wang et al., 2020c). It was observed in case of influenza virus that it can transmit more readily at lower temperatures (Lowen and Steel, 2014), since host immunity is likely to remain weakened in cold weather, this can further increase the vulnerability toward infection (Kudo et al., 2019). As the transmission process of coronaviruses is comparable with the influenza virus transmission (Lin et al., 2006), thus it can be expected that these processes are also applicable for the SARSCoV-2 transmission (Wang et al., 2020c).

\section{Other Environmental Factors}

Several other environmental factors can affect the link between mortality and temperature including air pollution (Cai et al., 2007), humidity (Jaakkola et al., 2014; Kudo et al., 2019), latitude (Bao et al., 2016). In this regard, socio-demographic factors including income, age, and gender (Bao et al., 2016) have also been reported to play roles. In a study, Chan et al. (2011) revealed that individuals who live at lower latitudes showed a strong adaptive capacity toward heat, and a relatively weak adaptive capacity was observed toward cold. These researchers also observed that the viability of SARS-CoV was much lower at higher relative humidity and higher temperatures (for example, relative humidity: over 95\%, and temperature: $38^{\circ} \mathrm{C}$ ). In a different study, it was revealed that humidity and temperature are linked with an increased risk of nCOVID-19 (Wang et al., 2020c). Interestingly, coronaviruses can persist on inanimate surfaces including plastic, glass, or metal for up to 9 days (Kampf et al., 2020).

\section{MOLECULAR PATHOGENESIS UNDERLYING nCOVID-19}

nCOVID-19 patients exhibit various clinical symptoms including cough, fever, fatigue, radiographic evidence of pneumonia, dyspnea, decreased or normal leukocyte counts, and myalgia (Huang et al., 2020). These aforesaid symptoms are also similar to MERS-CoV and SARS-CoV infections (Peiris et al., 2004). Even though nCOVID-19 pathogenesis is not well-understood, however the similar mechanisms used previously by MERS$\mathrm{CoV}$ and SARS-CoV can provide a lot of information regarding SARS-CoV-2 pathogenesis (Figure 1).

\section{Entry and Replication}

Spike protein (S protein) of coronavirus determines the viral entry into the host cells (de Wit et al., 2016). Interestingly, the envelope spike glycoprotein binds to its cellular receptor, angiotensin converting enzyme 2 (ACE2) for SARS-CoV (Li et al., 2003b) and SARS-CoV-2 (Wu et al., 2020b) (Figure 1), dipeptidyl peptidase 4 for MERS-CoV (Raj et al., 2013), and CD209L for SARS-CoV [26]. Although it was initially identified that SARS-CoV enters into cells by direct fusion of plasma membrane and virus (Simmons et al., 2004). However, Belouzard et al. (2009) revealed that a vital proteolytic cleavage process takes place at SARS-CoV S protein at position (S2') that facilitated the membrane fusion and infectivity of the virus. For membrane fusion, MERS-CoV also has evolved an aberrant 2 steps furin activation (Mille and Whittaker, 2014). Other than membrane fusion, entry of SARS-CoV was also found to be mediated by the clathrin-independent and -dependent endocytosis (Wang et al., 2008; Kuba et al., 2010). Following the entry of virus into the cells, RNA genome of SARS-CoV is released into the cytoplasm and is translated into 2 polyproteins and structural proteins, subsequently the viral genome starts to replicate (Perlman and Netland, 2009). The newly generated envelope glycoproteins are then inserted into the membrane of the endoplasmic reticulum or Golgi apparatus, and the 


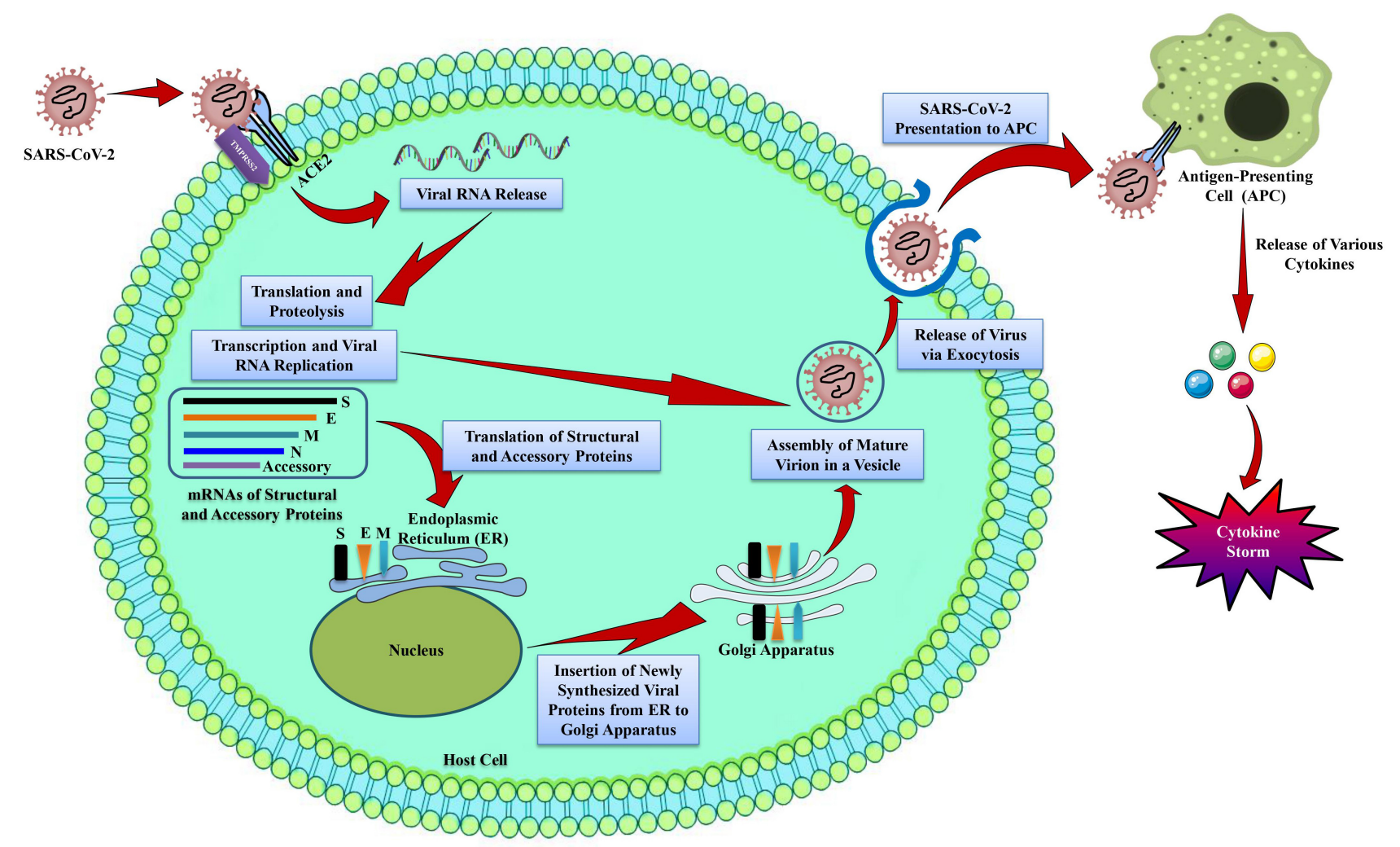

FIGURE 1 | The life cycle of SARS-CoV-2 in host cells. SARS-CoV-2 contains 4 structural proteins including spike (S), envelope (E), matrix/membrane (M), and nucleocapsid $(\mathrm{N})$, in association with various accessory proteins. SARS-CoV-2 enters into the host cell by binding with the S protein of the virus to the ACE2 receptor on the host cell. It has been found that S protein is cleaved into S1 and S2 by a cell-derived protease, where S1 binds with ACE2 receptor, and S2 is activated by the host serine protease TMPRSS2 and results in a fusion with the cell membrane. Following the entry into the host cell, SARS-CoV-2 takeovers the host cell machinery to transcribe, replicate, and translate its RNA genome and structural proteins before being reassembled, encapsulated, and exocytosed from the host cell. Following exocytosis, SARS-CoV-2 is presented to host antigen presenting cells (APCs), which eventually leads to the generation of various cytokines including, TNF- $\alpha$, CXCL-10, IL-1, and IL-6 (InvivoGen, 2020).

nucleocapsid is generated by the combination of nucleocapsid protein and genomic RNA. Subsequently, viral particles begin to germinate into the endoplasmic reticulum-Golgi intermediate compartment. Finally, virus particles containing vesicles then form fusion with the plasma membrane in order to release the virus (de Wit et al., 2016).

\section{Antigen Presentation in SARS-CoV-2 Infection}

When the SARS-CoV-2 enters into the cells, its antigen will be presented to the antigen presentation cells (APCs) (Figure 1), this process is crucial for the anti-viral immunity of the human body (Kumar et al., 2020). Peptides of antigens are presented via major histocompatibility complex (MHC; or human leukocyte antigen (HLA) in humans) and then identified by virusspecific cytotoxic $\mathrm{T}$ lymphocytes. Therefore, the understanding of antigen presentation (AP) of the virus will provide a better understanding of the pathogenesis of nCOVID-19. However, not much information is available regarding this, thus we can obtain information from previous studies on MERS-CoV and SARS-CoV. AP of SARS-CoV-2 mostly relies on MHC I molecules (Liu et al., 2010), nonetheless MHC II also plays roles in its presentation. Former studies revealed that many HLA polymorphisms associate with the susceptibility of SARS$\mathrm{CoV}$, for instance HLA-Cw*0801 (Chen et al., 2006b), HLA$\mathrm{B} * 0703$, HLA-DR B1*1202, and HLA-B*4601 (Keicho et al., 2009), while HLA-A $* 0201$, HLA-DR0301, and HLA-Cw1502 alleles are associated with the protection from SARS infection (Wang et al., 2011). In case of MERS-CoV, it was observed that MHC II molecules (for example HLA-DQB1*02:0 and HLA$\mathrm{DRB} 1 * 11: 01)$ were linked with the susceptibility to MERS-CoV infection (Hajeer et al., 2016). Other than mannose-binding lectin gene polymorphisms linked with AP are associated with the risk of SARS-CoV infection ( $\mathrm{Tu}$ et al., 2015). Indeed, the aforementioned findings will give us an important idea regarding the mechanism, prevention, and treatment of nCOVID-19.

\section{Humoral and Cellular Immune Responses}

AP subsequently induces the human body's humoral and cellular immune responses, which are then facilitated via virus-specific B and $\mathrm{T}$ cells. Like other common acute viral infections, antibodies including IgG and IgM are produced against SARS-CoV virus. 
It is estimated that at the end of week 12, SARS-specific IgM antibodies disappear. Whereas, SARS-specific IgG antibody can stay for a longer period, which is suggesting that IgG mainly has a protective function ( $\mathrm{Li}$ et al., 2003a). Furthermore, it was also found that SARS-specific IgG antibodies mainly are Nspecific and S-specific antibodies (de Wit et al., 2016). Most of the studies have focused on cellular immune responses, as compared to the humoral immune responses in case of coronavirus. Recent findings have revealed that the levels of $\mathrm{CD} 8^{+}$and $\mathrm{CD}_{4}^{+} \mathrm{T}$ cells in the peripheral blood of nCOVID19 individuals were significantly decreased, as confirmed by increased percentages of CD38 (CD8 39.4\%) and HLA-DR (CD4 3.47\%) double-positive fractions (Xu et al., 2020). Likewise, acute phase response in individuals with nCOVID-19 is linked with a marked decrease of $\mathrm{CD}^{+} \mathrm{T}$ and $\mathrm{CD} 4^{+} \mathrm{T}$ cells. Interestingly, it was found that although there is no presence of antigen, $\mathrm{CD} 8^{+}$, and $\mathrm{CD} 4^{+}$memory $\mathrm{T}$ cells can last for 4 years in individuals who have recovered from SARS-CoV and can perform IFN$\gamma$ generation, delayed-type hypersensitivity response and $\mathrm{T}$ cell proliferation (Fan et al., 2009). After 6 years of infection with SARS-CoV, specific T-cell memory responses to the SARS-CoV S peptide library can still be identified in 14 of 23 recovered SARS individuals (Tang et al., 2011). In mouse models, specific $\mathrm{CD}^{+} \mathrm{T}$ cells also exhibited similar activity in the clearance of MERS-CoV (Zhao et al., 2014). Indeed, these results might be useful in the rational designing of an effective vaccine against SARS-CoV-2.

\section{Cytokine Storm in nCOVID-19}

Acute respiratory distress syndrome (ARDS) is considered as the major cause of nCOVID-19-related death. In the early stages of the epidemic, 6 out of the 41 admitted patients with confirmed nCOVID-19 died owing to ARDS (Huang et al., 2020). This ARDS is found to be the main immunopathological characteristic of SARS-CoV, MERS-CoV, and SARS-CoV-2 infections ( $\mathrm{Xu}$ et al., 2020). Cytokine storm is the major characteristic of ARDS. This storm is a fatal uncontrolled systemic inflammatory response that takes place because of the high secretions of chemokines (i.e., C-X-C motif chemokine 10 [CXCL10], CXCL9, CXCL8, C-C motif chemokine ligand 5 [CCL5], CCL3, CCL2, etc.) and pro-inflammatory cytokines (i.e., transforming growth factor- $\beta$ [TGF $\beta]$, tumor necrosis factor alpha $[\mathrm{TNF} \alpha]$, interleukin 33 [IL-33], IL-18, IL-12, interferon gamma [IFN $\gamma]$, IL-6, IL-1 $\beta$, IFN- $\alpha$, etc.) via immune effector cells in case of SARS-CoV infection (Cameron et al., 2008; Williams and Chambers, 2014; Channappanavar and Perlman, 2017; Huang et al., 2020) as shown in Figure 1. Like SARS-CoV, MERS patients showed increased levels of CXCL-10, CXCL8, CCL5, IFN- $\alpha$, and interleukin 6 (IL-6) in serum as compared to individuals with the mild to moderate disease (Min et al., 2016). In the human body, a powerful cytokine storm will induce an aggressive attack by the immune system, which will lead to multiple organ failure and ARDS, and will ultimately result in death in severe novel coronavirus infection, as like MERS-CoV and SARS-CoV infection (Xu et al., 2020).

\section{Immune Evasion by SARS-CoV-2}

Various strategies are used by viruses including SARS-CoV and MERS-CoV to evade immune responses for their better survival in host cells. The pattern recognition receptors (PRRs) can identify the evolutionarily conserved microbial structures called pathogen-associated molecular patterns. Nonetheless, MERS$\mathrm{CoV}$ and SARS-CoV can stimulate the generation of doublemembrane vesicles lacking PRRs and subsequently can replicate in these vesicles, thus evading the host detection of their doublestrand RNA (dsRNA) (Snijder et al., 2006). IFN-I (IFN- $\beta$ and IFN- $\alpha$ ) plays a protective function on MERS-CoV and SARS$\mathrm{CoV}$ infection, however the IFN-I mechanism is suppressed in infected mouse models (Channappanavar et al., 2016, 2019). Interestingly, by directly interacting with the dsRNA, MERSCoV's accessory protein $4 \mathrm{a}$ might block the stimulation of IFN at the level of melanoma differentiation-associated protein 5 activation (Niemeyer et al., 2013). IFN $\beta$ promoter activation and transportation of IFN regulatory factor 3 to the nucleus can be inhibited by the ORF5, ORF4b, ORF4a, and membrane proteins of MERS-CoV (Yang et al., 2013). SARS-CoV-2 can also affect the AP. In this regard, for instance, gene expression associated with AP is downregulated following MERS-CoV infection (Menachery et al., 2018). Therefore, it is vital to terminate the immune evasion of coronavirus to develop specific and effective therapies.

\section{CLINICAL MANIFESTATIONS OF nCOVID-19 PATIENTS}

Following an incubation period of around 5.2 days, the symptoms of SARS-CoV-2 infection appear (Li et al., 2020b). It takes around 6 to 41 days from the first appearance of the symptoms to death, along with a median of 14 days (Wang et al., 2020d). However, the aforesaid durations depend on various factors including the patient's age and status of the immune system. This duration was found to be shorter for individuals older than 70-years old as compared to the individuals who are under the age of 70 (Wang et al., 2020d). At the onset of the disease, the most commonly observed symptoms are cough, fatigue, and fever (Figure 2). In addition to this, various other symptoms including headache, lymphopenia, dyspnea, sputum production, diarrhea, and hemoptysis (Graham Carlos et al., 2020; Huang et al., 2020; Ren et al., 2020; Wang et al., 2020d). Pneumonia has also been identified by computed tomography scan in nCOVID-19 patients, Unfortunately, various aberrant clinical features including ground-glass opacity (GGO), acute cardiac injury, and ARDS led to death (Huang et al., 2020). Occasionally, in subpleural areas of both lungs, the multiple peripheral GGOs were detected (Lei et al., 2020) and these triggered both localized and systemic immune responses, which collectively raised the level of inflammation. Unfortunately, treatment with interferon inhalation did not result in any clinical benefit, rather it aggravated the condition via facilitating pulmonary opacities (Lei et al., 2020).

Indeed, some of the symptoms of nCOVID-19 are similar to the earlier betacoronavirus including dyspnea, dry cough, 


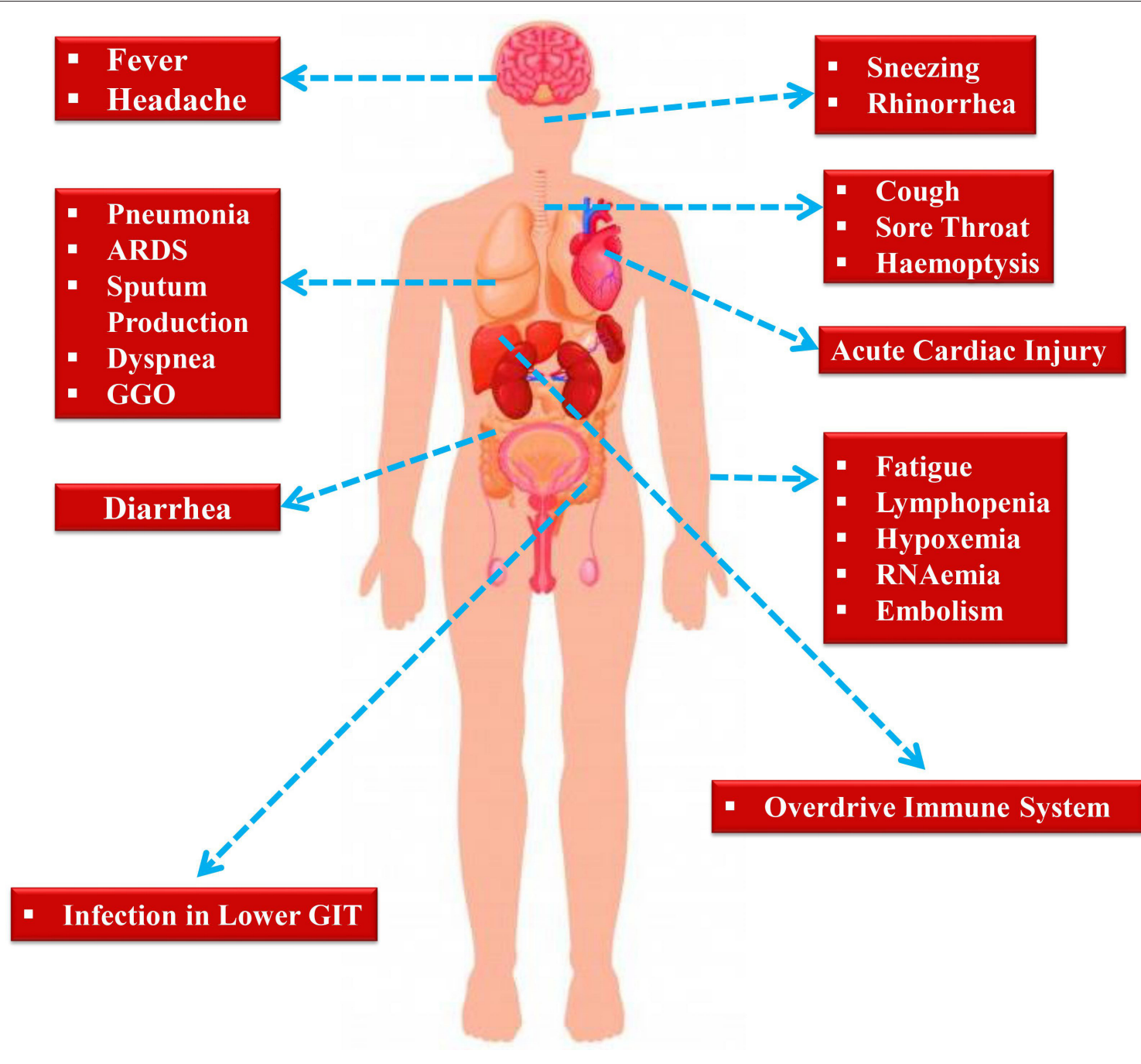

FIGURE 2 | Symptoms exhibited by nCOVID-19 patients.

fever, and bilateral GGOs (Huang et al., 2020). Nonetheless, there are some unique clinical manifestations of nCOVID-19 such as sore throat, sneezing, rhinorrhea (Lee et al., 2003; Assiri et al., 2013). As revealed by chest radiographs following admission, in some cases it was observed that an infiltrate in lung's upper lobe is linked with growing dyspnea with hypoxemia (Phan et al., 2020). Although nCOVID-19 exhibited digestive disorders like diarrhea, only a small proportion of SARS-CoV or MERS-CoV showed similar gastrointestinal symptoms. Thus, testing urine and fecal samples are important to eliminate a possible alternative mode of transmission (Lee et al., 2003; Assiri et al., 2013). Henceforth, developing methods to detect different routes of transmission for example urine and fecal samples are immediately required to develop ways to suppress and/or minimize the transmission and also to discover therapies to treat nCOVID-19.

Recently, it has been observed that nCOVID-19 might predispose to both arterial and venous thromboembolic disease because of immobilization, hypoxia, inflammation, and diffuse intravascular coagulation (Chen et al., 2020b; Guan et al., 2020; Klok et al., 2020; Wang et al., 2020a; Zhou et al., 2020). Furthermore, it was also revealed that respiratory failure in the disease is not only driven by the ARDS, rather microvascular thrombotic activities might also contribute in this regard (Grillet et al., 2020). Therefore, Klok et al. (2020) have strongly suggested to administer pharmacological agents in a prophylactic manner to all the intensive care unit (ICU) nCOVID-19 patients.

\section{DIAGNOSIS OF nCOVID-19 PATIENTS}

For any given emergency department (ED) visiting patients with the symptoms of fever and respiratory diseases, healthcare workers must need to get a travel history in detail from that patient. If a patient shows flu-like symptoms and has a travel history to a country or area with confirmed nCOVID-19 cases 
or if the patient came into close contact with a confirmed nCOVID-19 patient in the last 14 days then the patient ought to be considered as a patient under investigation (PUI) (NPR, 2020). It needs to be noted that here close contact means any individual who was within six feet of an individual with confirmed nCOVID-19 for an extended period. Furthermore, any individual who came into direct contact with the secretions of any nCOVID-19 patient will also be considered as a close contact.

Individuals who have traveled from high-risk countries or areas with confirmed nCOVID-19 cases and members of a family who are suffering from nCOVID-19 and not staying at home care or not maintaining isolation precautions are regarded as highrisk exposures. While medium risk exposures involve individuals who have traveled from low-risk countries or areas and family members are stringently maintaining appropriate home care and adhering with proper isolation precautions (WHO, 2020e). In contrast, low-risk exposures involve those individuals who were in the same indoor environment (for example in a waiting hall) for a longer period with nCOVID-19 patients but did not come into close contact.

Molecular assays of respiratory specimens are performed for diagnosis purposes usually at the regional referral laboratories designated by WHO (Kaiser Health News, 2020). For regional testing, the CDC started distributing nCOVID-19 test kits on February 7 (WHO, 2020a). nCOVID-19 test is getting more widely available day by day. For hospitals or institutions where nCOVID-19 test is not available, the only option is the testing by CDC. nCOVID-19 should be tested on an urgent basis for the PUI cases. An individual should be removed from PUI status only if that individual is fully evaluated clinically and has consulted with proper healthcare professionals.

\section{KEY MESSAGES AND MEASURES FOR nCOVID-19 PREVENTION}

The mode of SARS-CoV-2 transmission is still complex. Guidelines for nCOVID-19 prevention is mainly based on the previously developed guidelines for SARS and MERS and also on the intervening guidelines provided by $\mathrm{CDC}$ and WHO (CDC, 2020a,b; WHO, 2020a). Before or upon arrival in ED, a PUI ought to be identified by the hospitals to protect the healthcare professionals and other patients. Prevention measures should involve maintaining hand and respiratory hygiene and also screening questions including travel history. Following a PUI identification, both local health department and hospital infection control ought to be immediately notified to avert further spread among healthcare professionals and other patients. A surgical mask must need to be given to any PUI and need to be isolated in a private room or if possible in a negative pressure room (WHO, 2020a).

As like SARS and MERS, nCOVID-19 is also found to spread through the airborne route. Therefore, surgical face masks might be beneficial to prevent sneeze and cough-related larger fluid droplets, however they are less likely to prevent small airborne contaminants (Yee et al., 2020). In this regard, respirators containing air filters and adequate seal should be more beneficial
(Tran et al., 2012; Smith et al., 2016). In healthcare settings, right use of respirators and personal protective equipment and proper hand hygiene are likely to prevent transmission (Cowling et al., 2009; Radonovich et al., 2019; Yee et al., 2020). If a patient requires hospital admission and there is no private or separate room for that patient, then that patient needs to be taken to an adequate facility containing institution. Isolated rooms and care provide would need to be customized in a way that reduces the exposure of healthcare providers to the patient. Indeed, along with an eye shield, all the healthcare providers must take measures to prevent contact with droplets and to maintain airborne precautions. Since the risk of transmission is much higher during the aerosol-generating procedures (such as intubation), in these cases the importance of PPE is enormous (Raboud et al., 2010; CDC, 2020a). Still, it remains not known, regarding how long nCOVID-19 can stay airborne following a patient leaves the room. Respiratory protection is essential to enter into the vacated room.

\section{Effectiveness of Personal-Level Prevention}

Since still there is no specific drug to treat nCOVID-19, therefore the best approach will be taking preventative measures at a personal level including avoiding public transport, unnecessary travel, contact with nCOVID-19 suspected individuals, and so on.

\section{Importance of Hand Washing}

Indeed, the significance of maintaining frequent and proper hand hygiene is paramount. Like other coronaviruses, SARS$\mathrm{CoV}-2$ has a lipid envelope, thus proper hand-washing with soap can break apart that lipid envelope and therefore can make it difficult or even impossible for the virus to infect humans. So far, this proper hand-washing is considered as the most effective preventative measure. In addition, duration of hand-washing with soap is also equally important. CDC has recommended that effective hand-washing should last at least for $20 \mathrm{~s}$. In a study, Borchgrevink et al. (2013) showed that out of 3,749 individuals in a college town environment, only 5\% of those individuals properly followed the hand-washing rules (i.e., washing, rubbing, and rinsing). This finding indicates that there is a poor understanding of the significance of proper handwashing among the general people. Therefore, awareness among people should be increased about the importance of frequent and proper hand-washing.

\section{Proper Use of Face Mask}

In order to form a physical barrier, the WHO has recommended the use of a face mask by those individuals who are showing respiratory symptoms (WHO, 2020b). However, healthy people are not required to use face masks. A typical surgical mask only provides one-way protection and can avert the spreading of droplets during coughing and sneezing to the surrounding areas. Healthcare professionals who are treating or in contact with a suspected or confirmed nCOVID-19 patient must need to wear a specialized respirator (for example N95 or its equivalent) to effectively prevent the droplets entry and thus can reduce the chance of acquiring the infection (Bae et al., 2020; WHO, 2020b). Strict precautionary measures must need to be taken by the 
individuals during handling affected individual's body secretions including sputum, urine, or stools (Yeo et al., 2020).

\section{THERAPEUTIC OPTIONS FOR nCOVID-19 PATIENTS}

\section{Inhibitors of RNA-Dependent RNA Polymerase \\ Remdesivir}

Out of all the investigational drugs, remdesivir (Figure 3) has appeared as the most effective and promising antiviral drug (Li and De Clercq, 2020). This antiviral drug targets RNAdependent RNA polymerase (RdRp) of the virus while escaping proofreading via viral exoribonuclease, (Agostini et al., 2018) which can ultimately lead to early termination of viral RNA transcription as given in Figure 4. Interestingly, remdesivir is a phosphoramidate prodrug and has a wide range of activities against numerous virus families, such as pneumoviridae, paramyxoviridae, filoviridae, and orthocoronavirinae (for example pathogenic MERS-CoV and SARS-CoV) (Sheahan et al., 2017; Martinez, 2020).

In a COVID-19 mouse model, when remdesivir was administered prophylactically and as early therapeutic intervention, it significantly decreased the pulmonary viral load, which ultimately reduced the progression of the disease and significantly improved respiration (Sheahan et al., 2017). In tissue culture models, Brown et al. (Brown et al., 2019) revealed that remdesivir showed half-maximal effective concentration $\left(\mathrm{EC}_{50}\right)$ of $0.074 \mathrm{mM}$ and $0.069 \mathrm{mM}$ for MERS-CoV and SARS-CoV,<smiles>CCC(CC)COC(=O)[C@H](C)N[P+](=O)(OCC1O[C@](c2ccccc2)(c2ccc3c(N)ncnn23)[C@@H](O)[C@@H]1O)Oc1ccccc1</smiles>

Remdesivir<smiles>NC(=O)c1nc(F)cnc1O</smiles>

Favipiravir<smiles>NC(=O)c1ncn(C2OC(CO)C(O)C2O)n1</smiles>

Ribavirin<smiles>Cc1cccc(C)c1OCC(=O)N[C@@H](Cc1ccccc1)C(O)CC(Cc1ccccc1)NC(=O)C(C(C)C)N1CCCNC1=O</smiles>

Lopinavir<smiles>CC(C)c1nc(CN(C)C(=O)NC(C(=O)NC(Cc2ccccc2)CC(O)[C@H](Cc2ccccc2)NC(=O)OCc2cncs2)C(C)C)cs1</smiles>

Ritonavir

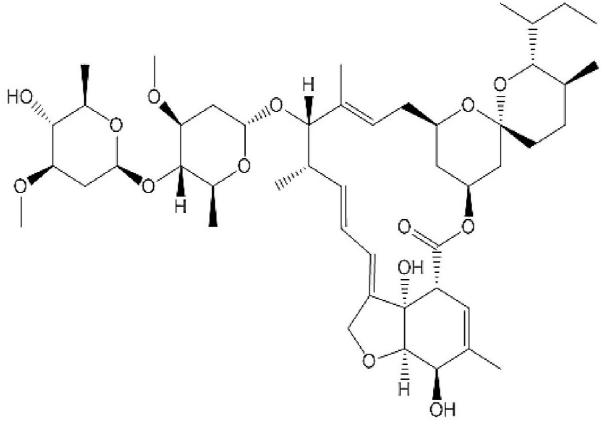

Ivermectin

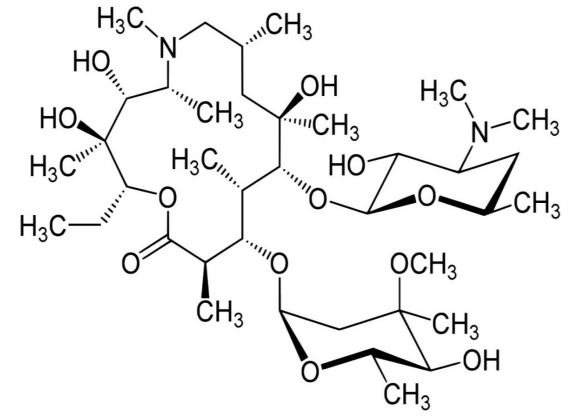

Azithromycin<smiles>CCN(CC)CCCC(C)Nc1ccnc2cc(Cl)ccc12</smiles>

Chloroquine<smiles>CCN(CCO)CCCC(C)Nc1ccnc2cc(Cl)ccc12</smiles>

Hydroxychloroquine<smiles>CC(=O)Oc1ccccc1C(=O)Nc1ncc([N+](=O)[O-])s1</smiles>

Nitazoxanide<smiles>CCOC(=O)c1c(CSc2ccccc2)n(C)c2cc(Br)c(O)c(CN(C)C)c12</smiles>

Umifenovir

FIGURE 3 | Chemical structures of potential investigational nCOVID-19 therapeutic agents. 


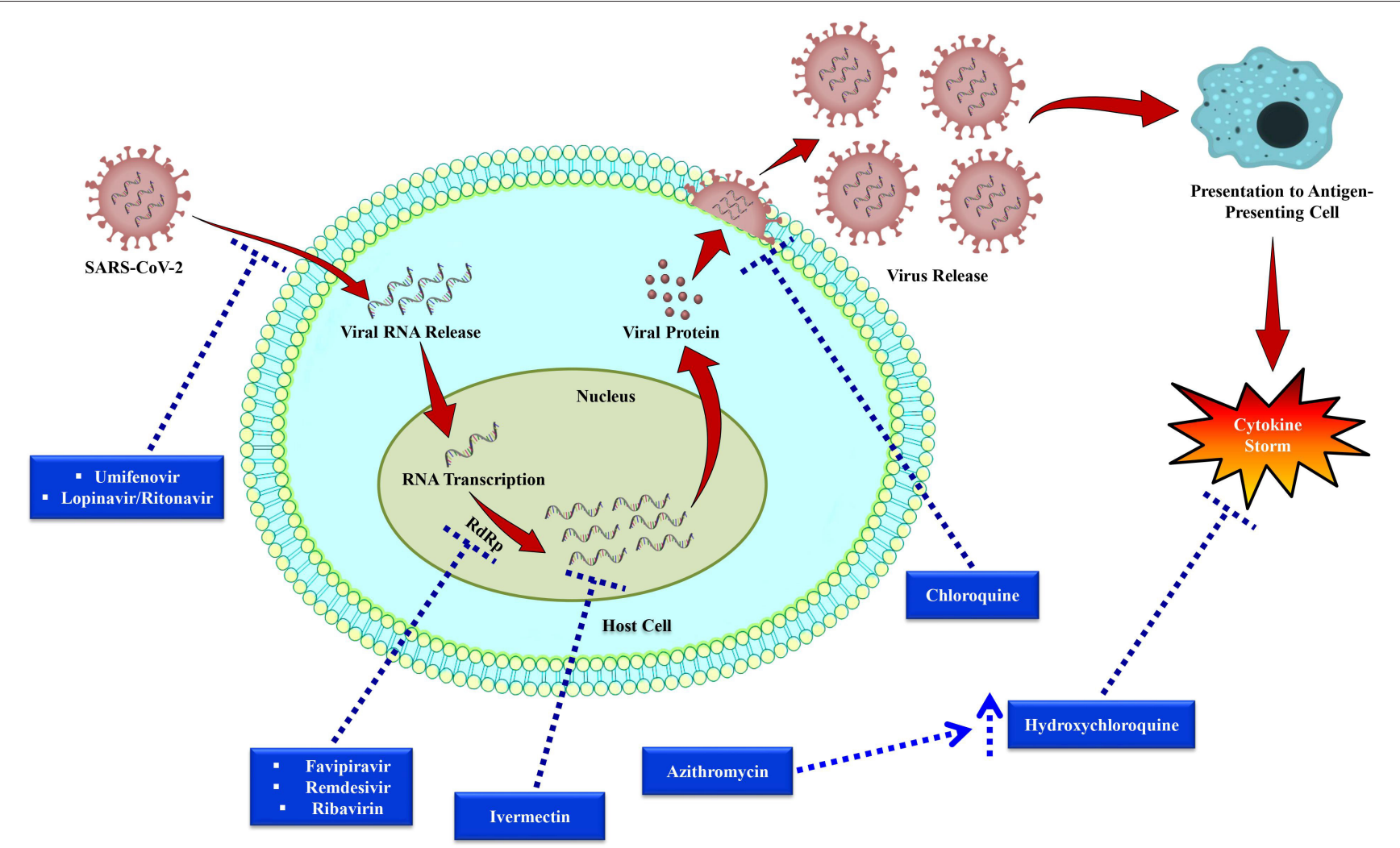

FIGURE 4 | Replication cycle of SARS-CoV-2 and potential anti-SARS-CoV-2 drug targets. Following bindings of SARS-CoV-2 particles with the cell receptors including dipeptidyl peptidase 4 (DPP4), aminopeptidase N (APN), and angiotensin-converting enzyme 2 (ACE2), RNA of the virus then enters into the host cell and viral RNA transcription takes place via RNA-dependent RNA polymerase (RdRp). After that viral protein synthesis takes place that is encapsulated and then released from the host cell. Dotted arrows have been used to indicate the drug targets of investigational therapies for nCOVID-19.

successively (Brown et al., 2019). Furthermore, remdesivir (within the submicromolar EC50s) also effectively inhibited zoonotic $\mathrm{CoV}$ and human CoVs (HCoV-229E and HCoV-OC43) (Brown et al., 2019; Ko et al., 2020). Similar results were also observed when remdesivir was administered therapeutically ( $12 \mathrm{~h}$ post-inoculation) and prophylactically ( $24 \mathrm{~h}$ before prior inoculation) in MERS animal (rhesus macaque) model (de Wit et al., 2020). Even 2 amino acid substitutions (V553L and F476L) in the non-structural protein 12 polymerase were found to show lower-level of resistance toward remdesivir (Agostini et al., 2018).

In humans, pharmacokinetic data of remdesivir is not available. However, it has been revealed in rhesus monkeys that intravenous remdesivir administration at the dose of 10 $\mathrm{mg} / \mathrm{kg}$ increased the intracellular concentration (over $10 \mathrm{mM}$ ) of active triphosphate form in peripheral blood mononuclear cells for a minimum of $24 \mathrm{~h}$, (Warren et al., 2016) which is indicating its clinical significance in nCOVID-19 treatment. Furthermore, human safety data of remdesivir are available online (Mulangu et al., 2019). In USA, the first patient with confirmed nCOVID-19 was effectively treated with remdesivir for the advancement of pneumonia on 7th day of hospital admission in January, 2020 (Holshue et al., 2020). Moreover, to assess its efficacy and safety to treat individuals with confirmed nCOVID-19, phase III clinical trials (ClinicalTrials.gov, 2020e) have been started in March 2020. In that study, individuals received $200 \mathrm{mg}$ of remdesivir on first day, subsequently received $100 \mathrm{mg} /$ day. Although remdesivir showed promising in vitro and clinical activity against coronavirus (Sheahan et al., 2017; Holshue et al., 2020), recently it has been reported that there are some uncertainties because of its multiple adverse effects including hepatotoxicity, rectal hemorrhage (Jean et al., 2020b).

\section{Favipiravir}

In Japan, favipiravir (Figure 3) was primarily developed and approved as an anti-influenza drug (Shiraki and Daikoku, 2020; Wang et al., 2020b). This antiviral drug has a wide range of activities against various RNA viruses including rhinovirus, respiratory syncytial virus (RSV), and influenza. Former studies revealed that favipiravir was successfully used to treat infections associated with rabies, Lassa virus, and Ebola virus (Shiraki and Daikoku, 2020). Furthermore, favipiravir was also found to be effective to treat severe fever with thrombocytopenia syndrome (Shiraki and Daikoku, 2020). Nevertheless, favipiravir was found to be ineffective against DNA viruses. 
Favipiravir is a potent antiviral drug that selectively suppresses the RdRp of RNA viruses (Figure 4) Favipiravir is likely to produce resistant viruses, as compared to oseltamivir (Shiraki and Daikoku, 2020). Indeed, this feature of favipiravir can be beneficial in the treatment of nCOVID-19. To treat influenza, favipiravir's recommended oral dose is $1,600 \mathrm{mg}$ two times on first day, subsequently $600 \mathrm{mg}$ twice/day from day 2 to 5 , and $600 \mathrm{mg}$ once/day on the sixth day. In recent times, initial findings of clinical trials have revealed that favipiravir exhibited significant activity in treating Chinese nCOVID-19 patients (Table 2) (Xinhua News Agency). In China, favipiravir has been approved to treat nCOVID-19 in March 2020. Furthermore, in China, randomized controlled trials involving nCOVID-19 patients are also assessing the efficacy of favipiravir plus baloxavir marboxil (an antiviral drug) (Qiu et al., 2020) and favipiravir plus IFN- $\alpha$ (Arab-Zozani et al., 2020).

\section{Ribavirin}

Ribavirin (Figure 3) is a RdRp inhibitor (Figure 4) used to treat various viral infections, for example, infections caused by RSV and hepatitis $\mathrm{C}$ virus (HCV) (Ogawa and Morisada, 2002). It was revealed by in vitro studies that when ribavirin was administered at a concentration of $50 \mathrm{mg} / \mathrm{mL}$, it showed effective antiviral activity against SARS-CoV (Chan et al., 2015). Unfortunately, this antiviral drug was found to decrease the level of hemoglobin, therefore it can be detrimental for individuals with respiratory distress (Martinez, 2020).

\section{Viral Entry Inhibitors}

\section{Umifenovir}

Umifenovir (Figure 3) is a potent antiviral agent that has a wide-range of activities against various viruses including $\mathrm{HCV}$, influenza A and B viruses (Boriskin et al., 2008). Umifenovir's mechanism slightly varies with different viruses. It has been revealed that umifenovir suppresses the fusion of the virus with the host cell membrane (Figure 4), thus the subsequent viral entry into the host cell is inhibited (Boriskin et al., 2008).

\section{Lopinavir/Ritonavir}

In a clinical trial, it has recently been observed that lopinavir/ritonavir (LPV/r, Figure 3) protease inhibitors that are mainly used in human immunodeficiency virus (HIV) treatment did not significantly improve the nCOVID-19 symptoms (Cao et al., 2020). Furthermore, in a different study, effect of umifenovir plus LPV/r was compared with the sole treatment with LPV/r to treat nCOVID-19 (Deng et al., 2020). The findings of that study revealed that better effects were observed with the treatment of umifenovir plus $\mathrm{LPV} / \mathrm{r}$ in comparison with the sole $\mathrm{LPV} / \mathrm{r}$ treatment (Deng et al., 2020). However, more studies are required to evaluate the incidence of resistance and efficacy. As coronavirus becomes activated on the membrane of the host cell, thus combination of $\mathrm{LPV} / \mathrm{r}$ and umifenovir are likely to inhibit/prevent the viral entry into the host cell (Figure 4). Besides, there is also a need regarding a better

TABLE 2 | Potential investigational therapies for nCOVID-19.

\begin{tabular}{|c|c|c|c|c|}
\hline Drug class & Drug & Mechanism of action & Outcome & References \\
\hline \multirow[t]{5}{*}{ Antiviral agents } & Remdesivir & $\begin{array}{l}\text { Inhibits viral RNA-dependent RNA } \\
\text { polymerase (RdRp) }\end{array}$ & $\begin{array}{l}\text { Showed promising in vitro and clinical } \\
\text { activity against coronavirus }\end{array}$ & $\begin{array}{l}\text { Brown et al., 2019; } \\
\text { ClinicalTrials.gov, 2020e }\end{array}$ \\
\hline & Favipiravir & & $\begin{array}{l}\text { Exhibited excellent activity in treating } \\
\text { nCOVID-19 patients }\end{array}$ & Xinhua News Agency, 2020 \\
\hline & Ribavirin & & $\begin{array}{l}\text { It showed effective antiviral activity against } \\
\text { SARS-CoV, but can be detrimental for the } \\
\text { patients with respiratory distress }\end{array}$ & $\begin{array}{l}\text { Chan et al., 2015; Martinez, } \\
2020\end{array}$ \\
\hline & Umifenovir & Inhibits entry of virus into the host cell & It can inhibit viral entry into the host cell & Boriskin et al., 2008 \\
\hline & $\begin{array}{l}\text { Lopinavir/ritonavir } \\
(\mathrm{LPV} / \mathrm{r})\end{array}$ & & $\begin{array}{l}\text { Combination of umifenovir and LPV/r } \\
\text { showed better activity as compared to the } \\
\text { sole use of LPV/r in nCOVID-19 treatment }\end{array}$ & Deng et al., 2020 \\
\hline \multirow[t]{2}{*}{ Antimalarials } & Chloroquine & $\begin{array}{l}\text { Prevents the viral fusion with the cell } \\
\text { membrane of the host cell }\end{array}$ & Findings from in vitro studies are promising & $\begin{array}{l}\text { Vincent et al., 2005; Cortegiani } \\
\text { et al., 2020; Wang et al., 2020b }\end{array}$ \\
\hline & Hydroxychloroquine & Controls cytokine storm & $\begin{array}{l}\text { Showed excellent in vitro activity as well as } \\
\text { more potent and less likely to interact with } \\
\text { other drugs as compared to chloroquine }\end{array}$ & Yao et al., 2020 \\
\hline $\begin{array}{l}\text { Macrolide } \\
\text { antibiotics }\end{array}$ & Azithromycin & $\begin{array}{l}\text { Enhances the anti-SARS-CoV-2 } \\
\text { effect of hydroxychloroquine }\end{array}$ & $\begin{array}{l}\text { Combined use led to a reinforcement of } \\
\text { hydroxychloroquine's efficacy in treating } \\
\text { nCOVID-19 patients }\end{array}$ & Gautret et al., 2020 \\
\hline $\begin{array}{l}\text { Glycopeptide } \\
\text { antibiotics }\end{array}$ & $\begin{array}{l}\text { Teicoplanin and its } \\
\text { derivatives }\end{array}$ & $\begin{array}{l}\text { Inhibits cathepsin L and cathepsin B } \\
\text { in host cells }\end{array}$ & $\begin{array}{l}\text { They can selectively suppress the effects } \\
\text { of cathepsins B and } L \text { in the host cell }\end{array}$ & $\begin{array}{l}\text { Wang et al., 2016; Zhou et al., } \\
2016\end{array}$ \\
\hline \multirow[t]{2}{*}{ Antiparasitic agent } & Ivermectin & Dissociates IMP $\alpha / \beta 1$ heterodimer & $\begin{array}{l}\text { Recent in vivo study has been } \\
\text { demonstrated that it can remarkably } \\
\text { decrease the level of viral RNA }\end{array}$ & Caly et al., 2020 \\
\hline & Nitazoxanide & $\begin{array}{l}\text { Interferes with the host-regulated } \\
\text { pathways linked with viral replication }\end{array}$ & $\begin{array}{l}\text { Exerted a potent in vitro antiviral activity } \\
\text { against SARS CoV-2 }\end{array}$ & Wang et al., 2020b \\
\hline
\end{tabular}


understanding of the more precise mechanisms to improve future clinical applications.

\section{Inhibitors of Viral Fusion and Cytokine Storm \\ Chloroquine}

Chloroquine (Figure 3) is mainly used as an antimalarial drug. Furthermore, chloroquine is also used to treat various autoimmune disorders including rheumatoid arthritis and lupus erythematosus. In an animal model, it has recently been observed that chloroquine can also play a role as a potent antiviral drug against various viruses including influenza $\mathrm{H} 5 \mathrm{~N} 1$ (Yan et al., 2013). Interestingly, chloroquine can prevent the viral fusion with the cell membrane of host cell by increasing endosomal $\mathrm{pH}$ (Figure 4). Glycosylation of SARS-CoV's cellular receptors can also be interfered by chloroquine (Vincent et al., 2005; Wang et al., 2020b). Even though findings from in vitro studies regarding chloroquine is auspicious $\left(\mathrm{EC}_{90}=6.90 \mathrm{mM}\right.$, used nCOVID-19-infected Vero E6 cells), however use of chloroquine to treat nCOVID-19 infection is a completely off-label use. Furthermore, this drug is not strongly indicated due to some of its safety reasons including QT prolongation with ventricular dysrhythmia and adverse reactions on the renal, hepatic, and hematologic systems (Cortegiani et al., 2020).

\section{Hydroxychloroquine}

Hydroxychloroquine (a chloroquine derivative, Figure 3) is also mainly used as antimalarial and anti-inflammatory drugs (Sinha and Balayla, 2020). It has been proposed that hydroxychloroquine controls cytokine storm (Figure 4), which takes place in critically ill late phase nCOVID-19 patients (Yao et al., 2020). As compared to chloroquine, hydroxychloroquine is more potent and their $\mathrm{EC}_{50}$ values are 5.47 and 0.72 , successively. In addition to this, hydroxychloroquine is less likely to interact with other drugs as compared to chloroquine. Moreover, in comparison with chloroquine phosphate, pharmacokinetic data confirmed that hydroxychloroquine is much more effective (5 days before) at inhibiting SARS-CoV-2 in vitro (Yao et al., 2020). It has been declared on March 26, 2020 by Taiwan CDC that hydroxychloroquine has a significant role in the treatment of nCOVID-19 patients. However, treatment with hydroxychloroquine is contraindicated for the patients who are pregnant or breastfeeding, allergic to hydroxychloroquine, glucose-6-phosphatase deficient, and for individuals with prolonged QT interval in electrocardiograms and retinopathy (Gautret et al., 2020).

\section{Enhancer of Anti-SARS-CoV-2 Effect of Hydroxychloroquine Azithromycin}

Previously, azithromycin (Figure 3) showed excellent in vitro activity against Ebola virus (Madrid et al., 2016). It was found that azithromycin was administered to individuals with viral infection, it prevented severe infections of respiratory tract in pre-school children (Bacharier et al., 2015). In a recent study, when azithromycin was administered (i.e., $500 \mathrm{mg}$ on first day, then $250 \mathrm{mg}$ per day from day 2-5), it remarkably reinforced the hydroxychloroquine's efficacy (when $200 \mathrm{mg}$ was administered 3 times/day for 10 days) to treat 20 severely ill nCOVID-19 patients (Figure 4). The mean serum concentration of hydroxychloroquine was $0.46 \pm 0.20 \mathrm{mg} / \mathrm{mL}$. It is assumed that this excellent virus eliminating activity was achieved owing to the use of the aforesaid combination therapy (Gautret et al., 2020). Therefore, use of azithromycin along with hydroxychloroquine can be an effective future alternative to remdesivir in nCOVID-19 treatment. However, in this regard, a possible complication related to prolonged QT interval should be taken into consideration.

\section{Inhibitors of Cathepsins B and L Teicoplanin and Its Derivatives}

Teicoplanin is a glycopeptide antibiotic and it has been revealed by Zhou et al. (Zhou et al., 2016) that teicoplanin exerted inhibitory activity $\left(\mathrm{IC}_{50}\right.$ as low as $330 \mathrm{~nm}$ ) against replication- and transcription-competent virus-like particles. Studies confirmed that teicoplanin can suppress the entry of MERS and SARS envelope pseudotyped viruses (Wang et al., 2016; Zhou et al., 2016). In terms of its mechanism, teicoplanin can selectively suppress the effects of cathepsins $\mathrm{B}$ and $\mathrm{L}$ in host cell. These proteases are involved with cleaving the viral glycoprotein permitting exposure of the receptor-binding domain of its core genome and then release into the cytoplasm of host cells (Zhou et al., 2016; Baron et al., 2020). Therefore, teicoplanin blocked the entry of Ebola virus in the late endosomal pathway. Also, the derivatives of teicoplanin including telavancin, dalbavancin, and oritavancin, were also found to block the entry of SARS, MERS, and Ebola viruses (Zhou et al., 2016). Collectively, these findings suggest that teicoplanin and its derivatives might play a vital role in inhibiting the viruses that are dependent on cathepsin $\mathrm{L}$ (Table 2).

\section{Immunomodulators} Ivermectin

Ivermectin (Figure 3) is an antiparasitic agent and it has broadspectrum of activity (Caly et al., 2020), Recent in vitro studies have revealed that this drug also has an antiviral effect against dengue and HIV viruses (Wagstaff et al., 2012). It has been found that the preformed IMP $\alpha / \beta 1$ heterodimer is accountable for the transport of viral protein into the nucleus and ivermectin can dissociate this heterodimer. Since this transport of viral protein into the nucleus is important for the replication cycle and suppression of the host's antiviral response, thus targeting this viral protein transport might prove as a significant target in the development of therapeutic agents against RNA viruses (Caly et al., 2012; Yang et al., 2020a). Following $48 \mathrm{~h}$ of nCOVID19 infection, a recent in vivo study has been demonstrated that ivermectin can decrease the level of viral RNA (Figure 4) up to 5,000-times (Caly et al., 2020). Since ivermectin has an established safety profile as an antiparasitic agent, thus now it is needed to establish a safe and effective dose of this drug in clinical trials to treat nCOVID-19 infection. 


\section{Nitazoxanide}

Nitazoxanide (Figure 3) is an effective antiparasitic and antiviral drug (Rossignol, 2016). This drug has a broad-spectrum in vitro antiviral activity against a range of viruses including RSV, rotavirus, parainfluenza, influenza, and coronavirus (Rossignol, 2016). In Vero-E6 cells, nitazoxanide exerted a potent in vitro antiviral activity against SARS CoV-2 $\left(\mathrm{EC}_{50}=2.12 \mu \mathrm{M}\right.$, at $48 \mathrm{~h}$ ) (Wang et al., 2020b). Furthermore, this strong antiviral effect is in line with the observed $\mathrm{EC}_{50}$ values for nitazoxanide $\left(\mathrm{EC}_{50}=0.92 \mu \mathrm{M}\right)$ and tizoxanide (an active metabolite of nitazoxanide) $\left(\mathrm{EC}_{50}=0.83 \mu \mathrm{M}\right)$ against MERS-CoV in LLCMK2 cells (Rossignol, 2016). In terms of its mechanism of action, it is believed that nitazoxanide has potent antiviral effect because of its ability to interfere with the host-regulated pathways associated with viral replication instead of the virus-specific pathways (Rossignol, 2016). Therefore, studies were carried out to evaluate the ability of this drug to treat influenza and other related acute respiratory infections. In the phase IIb/III of a clinical trial, positive effects of nitazoxanide were observed in the management of influenza symptoms, where $600 \mathrm{mg}$ of nitazoxanide was orally administered twice a day (Haffizulla et al., 2014). Unfortunately, in phase II clinical trial it was observed that nitazoxanide neither alleviated the symptoms nor decrease the length of stay in hospitals of individuals infected with respiratory viruses (Gamiño-Arroyo et al., 2019). However, in vitro data regarding the activity of nitazoxanide against coronavirus is promising. Therefore, further studies are required to estimate its potential in nCOVID-19 treatment.

\section{Janus Kinase Inhibitors}

Baricitinib most commonly used in rheumatoid arthritis treatment. This drug is a reversible and selective inhibitor of Janus kinase 1 (JAK1) and JAK2. It has been found that these latter mentioned enzymes transduce intracellular signals for growth factors and cytokines associated with immune response, inflammation, and haematopoiesis. Moreover, this JAK inhibitor blocks the activities of AP2-associated with protein kinase 1, which ultimately prevents viral binding with the alveolar epithelium (Mayence and Vanden Eynde, 2019). It has also been indicated that baricitinib might be used as an additional therapy for the COVID-19 treatment (Richardson et al., 2020). In order to determine the safety and efficacy of sarilumab, hydroxychloroquine, lopinavir/ritonavir, and baricitinib to treat 1,000 hospitalized COVID-19 patients, a non-randomized phase II clinical study has recently been started (Scavone et al., 2020). Other selective JAK inhibitors including ruxolitinib, fedratinib, and sunitinib might also be effective against COVID-19 in decreasing endocytosis of virus, inflammation, and levels of cytokines including IL-6 and IFN- $\gamma$ (Bekerman et al., 2017; ClinicalTrials.gov, 2020f; Favalli et al., 2020; Scavone et al., 2020; Stebbing et al., 2020).

\section{Convalescent Plasma}

Previously, convalescent plasma therapy was used as a terminal therapy to increase the survival rate of individuals with a range of viral infections including SARS, severe infection caused by Ebola virus, pandemic 2009 influenza A H1N1, H5N1 avian influenza
(Chen et al., 2020a; Shen et al., 2020). Convalescent plasma therapy can be effective because viremia can be suppressed due to the presence of plasma immunoglobulin antibodies in recovering patients. In a study, Shen et al. (2020) evaluated the effect of convalescent plasma therapy in 5 severely ill nCOVID-19 patients with ARDS. In that study, convalescent plasma was transfused in those patients with a novel coronavirus-specific antibody (neutralization titer $>40$ and binding titer $>1: 1000$ ). The used convalescent plasma of that study was obtained from five nCOVID-19-recovered individuals. The obtained convalescent plasma was then administered to the 5 patients (in between 10 and 22 days following admission) along with methylprednisolone and antiviral drugs. After convalescent plasma transfusion, clinical conditions of the patients were found to be improved, including decreased viral loads (patients became nCOVID-19 negative within 12 days), elevated level of SARS-CoV-2-specific enzyme-linked immunosorbent assay (ELISA), neutralizing antibody titers, normalized body temperature (within 3 days in four/five patients), improved ARDS (four patients at 12 days following transfusion), successful weaning from mechanical ventilation (three participating individuals within 2 weeks of therapy), increased partial pressure of oxygen/fraction of inspired oxygen, and reduced score in sequential organ failure assessment. Out of the 5 participants, 2 of them were in stable condition (at 37 days following transfusions), while 3 of them were discharged from the hospital (following 51, 53, and 55 days of staying in the hospital) (Shen et al., 2020). Finally, the researchers summarized that although there were a small number of participants in this study, they suggested the therapy with convalescent plasma can be effective in the nCOVID-19 treatment (Shen et al., 2020).

\section{Monoclonal or Polyclonal Antibodies and Other Potential Therapies}

As a prophylactic measure and therapy, monoclonal and polyclonal antibodies (targeting hemagglutinin binding) have been recommended to treat various viral infections including influenza (Beigel et al., 2019). The effectiveness of these antibodies against MERS-CoV largely encouraged the recent efforts to develop monoclonal and polyclonal antibodies against coronaviruses (Sheahan et al., 2017). For instance, in a phase I trial, SAB-301 (a human polyclonal antibody) which was produced in transchromosomic cattle was found to be safe and better tolerated in healthy participants (Beigel et al., 2019). In a study, Cockrell et al. (2016) revealed in mouse models that human monoclonal antibodies (mAbs)-based immunotherapy only mediated protection in the early stage of MERS (Martinez, 2020).

Many in vitro analyses showed that $\mathrm{S}$ protein of SARS-CoV is crucial to mediate the viral entry into the host cells. In addition to this, the cleavage and subsequent activation of the $S$ protein of SARS-CoV via a host cell's protease is vital for the entry of the virus (Glowacka et al., 2011). In cell cultures, it has been noticed that transmembrane serine protease 2 (TMPRSS2) is a vital protease of host cells that causes activation of S protein of SARS$\mathrm{CoV}$, therefore it was studied as an important target for antiviral drugs (Sheahan et al., 2017). Previously, camostat mesylate (an 
inhibitor of serine protease) showed inhibitory activity against TMPRSS2 (Kawase et al., 2012). Furthermore, K11777 (a cysteine protease inhibitor) exhibited significant inhibitory activity (at submicromolar range) against replication of MERS-CoV and SARS-CoV (Zhou et al., 2015). Sarilumab is a human monoclonal antibody and 3 clinical trials are ongoing to assess the safety and efficacy of this antibody (alone or along with other standard therapies) in nearly 1,500 COVID-19 patients (ClinicalTrials.gov, 2020a,d,f; Scavone et al., 2020).

Eculizumab (a monoclonal antibody) is approved to treat neuromyelitis spectrum disorders, refractory generalized myasthenia gravis, and atypical hemolytic uraemic syndrome. This monoclonal antibody inhibits the terminal portion of the inflammatory response-associated complement cascade. Although the function of the complement cascade in nCOVID-19 pathogenesis is not clear, numerous studies revealed that its suppression may effectively function as a therapeutic technique (Ip et al., 2005; Yuan et al., 2005; Gralinski et al., 2018). Due to these findings, eculizumab will be tested in the SOLID-C19 clinical trial to treat individuals with severe ARDS and nCOVID19 (ClinicalTrials.gov, 2020b). Currently, emapalumab (a monoclonal antibody) is being studied in an openlabel, randomized, phase II/III study to evaluate the safety and efficacy of this antibody in decreasing respiratory distress and hyper-inflammation in nCOVID-19 patients (ClinicalTrials.gov, 2020c).

In China, stem cells are currently being studied as a treatment for nCOVID-19. Tocilizumab (a mAb) is an immunosuppressive agent and is used to treat rheumatoid arthritis (Kaneko, 2013). This agent was designed to suppress the IL-6 binding with its receptors to alleviate cytokine storm syndrome. Tocilizumab is now being studied as a potential nCOVID-19 treatment (Jean et al., 2020b; Slater, 2020).

\section{Herbal Medicines}

In nCOVID-19 high-risk populations, traditional Chinese medicines were also regarded as a preventative measure, based on the traditional uses and anecdotal evidence of prevention of H1N1 pdm09 and SARS. Nonetheless, there is a lacking of clinical data regarding the effectiveness of these herbal medicines as an nCOVID-19 treatment (Cunningham et al., 2020; Luo et al., 2020). In China, several traditional medicines were widely used during the nCOVID-19 epidemic and 6 of these herbal medicines include Lianqiao (Fructus forsythia), Jinyinhua (Lonicerae Japonicae Flos), Gancao (Glycyrrhizae Radix Et Rhizoma), Baizhu (Atractylodis Macrocephalae Rhizoma, rhizome of Atractylodes macrocephala Koidz), Fangfeng (Saposhnikoviae Radix, dried root from the perennial herb Saposhnikovia divaricate), and Huangqi (Astragali Radix, dried root of Astragalus membranaceus Bge. Var. mongholicus). Indeed, stringent clinical studies are required with a large number of participants to demonstrate the preventive role of these traditional Chinese medicines (Cunningham et al., 2020; Luo et al., 2020).

\section{Adjunctive Medications Antimicrobial Agents}

The occurrence of co-infection can widely vary among the patients with confirmed nCOVID-19. Various reports suggest that several co-pathogens including viruses (such as rhinovirus, influenza, and HIV) and bacteria (for example Candida species, Mycoplasma pneumonia) can co-exist in these patients. Among them, influenza A virus was most commonly found to coexist (Jean et al., 2020b). Furthermore, nCOVID-19 patients with pneumonia were found to be commonly treated by the coadministration of anti-influenza drugs and antibiotics (Jean et al., 2020b). Therefore, careful selection of potential broadspectrum antibiotic(s) is required for the long-stay (over 6 days) hospitalized patients (Chou et al., 2019; Jean et al., 2020a).

\section{Corticosteroids}

Mixed clinical findings were observed with the use of corticosteroids to treat SARS-CoV infections. Although various reports suggested that there was no significant contribution of corticosteroids in clinical outcomes (Stockman et al., 2006). In contrast, it was suggested by a report that decreased mortality rate was observed due to the use of corticosteroids in critically ill patients (Chen et al., 2006a; Wu et al., 2020a). Unfortunately, several reports suggested worse outcomes including longer time for viral clearance, or elevated composite endpoint of ICU admission or even death, owing to the use of corticosteroids (Auyeung et al., 2005). In a cohort ( $n=309)$, a longer time in viral clearance was observed in the corticosteroids-receiving MERS$\mathrm{CoV}$ patients (Arabi et al., 2018). Nevertheless, in the same study, it was observed that there was an insignificant decrease in 90-day mortality in corticosteroids-receiving patients. Recent reports suggested that there was a decreased rate of mortality in nCOVID-19 patients with ARDS due to the use of corticosteroids (Wu et al., 2020a).

These findings suggest that use of corticosteroids resulted in inconsistent outcomes. However, corticosteroids might be beneficial for patients with cytokine-linked lung injury and those who might rapidly develop progressive pneumonia (Shang et al., 2020). Indeed, healthcare professionals need to carefully assess the risk and benefit ratio of corticosteroid use for each patient. This necessity to assess risk and benefit of corticosteroid use in individual patients and its careful dose consideration has been demonstrated in diagnosis and treatment guidelines from China's National Health Commission. As per that guideline, glucocorticoid (equivalent to methylprednisolone 1$2 \mathrm{mg} / \mathrm{kg}$ per day for three-five days or less) may be considered based on chest imaging and respiratory distress. Large-dose of glucocorticoids can suppress the immune system, this can result in delayed SARS-CoV-2 clearance (McCreary and Pogue, 2020). Recently, Chinese Thoracic Society recommended a lower dose of methylprednisolone ( $\leq 0.5-1 \mathrm{mg} / \mathrm{kg}$ per day) for a maximum of 7 days in selected patients, prior to treatment these selected patients should be carefully assessed for potential risks and benefits (Shang et al., 2020). More clinical studies are immediately required to elucidate the function of corticosteroids in nCOVID-19. 


\section{Angiotensin II Receptor Blockers, ACE Inhibitors, and Statins}

In a study, Yang et al. (2020b) mentioned that diabetes and cerebrovascular diseases were the commonly observed comorbidities in the non-survivors of nCOVID-19 in ICUs. Furthermore, Guan et al. (2020) also observed similar results in their study and these nCOVID-19 patients received angiotensin II receptor blockers (ARBs) or ACE inhibitors. Indeed, SARS$\mathrm{CoV}-2$ and SARS-CoV can bind with the ACE2 receptors on the epithelial cells of lung, kidney, and intestine (Fang et al., 2020). Therefore, when ARDS is not present, ARB or ACE inhibitors can be administered to nCOVID-19 patients. Increased activity of ACE2 was found to be linked with decreased severity of ARDS among individuals with RSV-caused lower respiratory tract infection (Wösten-van Asperen et al., 2013). Interestingly, Fedson (2016) revealed in their study that statins mainly target host response to infection, instead of the virus itself. These researchers also indicated that combination therapy with statins and ARB may induce the reversal of homeostatic processes, which will allow the self-recovery of individuals (Fedson et al., 2020).

\section{Non-steroidal Anti-inflammatory Drugs}

There is an argument regarding the usage of non-steroidal anti-inflammatory drugs (NSAIDs) like ibuprofen since it can increase the ACE2 receptors (Day, 2020). If the severely ill nCOVID-19 individuals suffer from fever, acetaminophen can be a good option to control body temperature as compared to other NSAIDs (Therapeutics Initiative, 2020).

\section{Anticoagulant Therapy}

Tang et al. (2020) confirmed that anticoagulant therapy by heparin (an anticoagulant) specially with low molecular weight heparin improved the prognosis in severely ill patients with nCOVID-19. Furthermore, 28-day mortality of heparin receivers was found to be lower as compared to the non-users among individuals with sepsis-stimulated coagulopathy scores 4 or Ddimer $>6$-times the upper limit of normal (Tang et al., 2020).

\section{Enhancing Immunity by Vitamins and Minerals in nCOVID-19}

\section{Vitamin A}

In human body, vitamin A plays various important functions including protecting mucosal and epithelium integrity, mediating growth and development, and proper maintenance of vision (Huang et al., 2018). Vitamin A is also essential for enhancing immune response and maintaining regulatory action in both humoral and cellular immune responses (Huang et al., 2018). In case of infants, supplementation with vitamin A was found to ameliorate antibody response following several vaccines including anti-rabies (Siddiqui et al., 2001) and measles vaccination (Huang et al., 2018). Moreover, an improved immune response to influenza virus vaccination has also been reported in children (2-8 years) who had a deficiency of vitamin $\mathrm{A}$ and $\mathrm{D}$ at baseline, following supplementation with vitamin $\mathrm{A}$ and D (Patel et al., 2019).

\section{Vitamin D}

Vitamin D has a significant contribution in modifying both adaptive and innate immune responses (Aranow, 2011). It has been revealed by epidemiological studies that there is a link between deficiency of vitamin $\mathrm{D}$ and elevated susceptibility to acute viral respiratory infections (Monlezun et al., 2015). It has also been suggested that vitamin D significantly modulates the innate immune responses against various viral respiratory infections including RSV, parainfluenza 1 and 2, and influenza A and B (Zdrenghea et al., 2017). Indeed, studies have revealed that there is a strong relationship between vitamin D deficiency and elevated risk of both lower and upper respiratory tract infections (Jolliffe et al., 2013). Nonetheless, conflicting and heterogeneity in dosage regimens and baseline vitamin D conditions in study populations were observed in randomized controlled trials (RCTs) (Jolliffe et al., 2013). In a study, Aglipay et al. (2017) observed no significant difference between the action of high-dose (2000 IU per day) vs. standard-dose (400 IU per day) vitamin D supplementation on viral upper respiratory tract infections (Aglipay et al., 2017). Nevertheless, only one-third of the study subjects received vitamin D at doses below $30 \mathrm{ng} / \mathrm{ml}$. Vitamin D increased the plasma level of TGF $\beta$ without ameliorating antibody generation in a RCT on the effect of vitamin D administration on influenza vaccine response in deficient elderly person (Goncalves-Mendes et al., 2019). In addition to this, it was also indicated in the latter mentioned RCT that vitamin D administration perhaps directed the polarization of lymphocyte toward a tolerogenic immune response (Goncalves-Mendes et al., 2019). In a different RCT, monthly administration of high-dose of vitamin D (100,000 $\mathrm{IU} /$ month) decreased the occurrence of acute respiratory infections in older long-term care residents as compared to a standard dose group (12,000 IU/month) (Ginde et al., 2017). Therefore, it is quite clear that the effect of vitamin $\mathrm{D}$ on antiviral immunity against respiratory infections is dependent on an individual's vitamin D status. Moreover, it has been confirmed that vitamin D supplementation is also useful in case of other viral infections, for instance, vitamin $\mathrm{D}$ addition to conventional Peg- $\alpha-2 b /$ ribavirin therapy for treatment-naive individuals with chronic HCV genotype 1 infection considerably ameliorated the viral response (Abu-Mouch et al., 2011), and similar action was also seen in individuals with HCV genotype 2-3 (Nimer and Mouch, 2012).

\section{Vitamin E}

Vitamin E possesses strong antioxidant property and it can modify host immune responses [14]. The deficiency of this vitamin can lead to impairment of both cellular and humoral immune responses (Moriguchi and Muraga, 2000). Some studies revealed that administration of vitamin $\mathrm{E}$ may exert harmful activities in case of infectious disease. Vitamin $\mathrm{E}$ increased the risk of pneumonia among 50-69 years old adult smokers (Hemilä and Kaprio, 2008). Similarly, vitamin E supplementation (200 IU/day) did not significantly reduce the respiratory tract infections in elderly nursing facility residents (Meydani et al., 2004). Nevertheless, in a small pilot RCT, positive activities of vitamin $\mathrm{E}$ were seen in the treatment of chronic hepatitis $\mathrm{B}$, 
where vitamin $\mathrm{E}$ administration markedly normalized the liver enzymes and HBV-DNA negativization (Andreone et al., 2001). Similarly, in a RCT, vitamin E supplementation increased anti$\mathrm{HBe}$ seroconversion and virological response in the pediatric population (Fiorino et al., 2017).

\section{Vitamin C}

Vitamin C plays a significant role as an enzymatic cofactor in numerous physiological reactions including immune potentiation, collagen synthesis, and hormone generation (Kim et al., 2013). In mouse models, it was revealed that vitamin $\mathrm{C}$ plays important role in the antiviral immune responses against the influenza A virus $(\mathrm{H} 3 \mathrm{~N} 2)$ via the elevated generation of IFN- $\alpha / \beta$, particularly at the early stages of infection (Kim et al., 2013). Nonetheless, no significant benefit has been observed in using mega-dose of vitamin $\mathrm{C}$ as a prophylactic measure to lower the incidence of common cold caused by viral infections (Hemilä and Chalker, 2013).

\section{Zinc}

Zinc (an essential trace element) contributes significantly in the growth, development, and maintenance of immune responses (Prasad, 2013; Read et al., 2019). The deficiency of zinc is linked with an enhanced susceptibility toward infectious diseases, for example, viral infections. An individual's zinc status is a vital factor that can affect the immune response against viral infections. Indeed, zinc-deficient individuals are at greater risk of developing infections including HCV or HIV (Read et al., 2019). Acevedo-Murillo et al. (2019) reported that there was a noticeable clinical improvement in the 103 children ( 1 month -5 years) with pneumonia in the zinc-receiving group as compared to placebo (Acevedo-Murillo et al., 2019). The researchers also confirmed that there was a rise in the cytokine response in Th1 pattern (INF- $\gamma$ and IL-2) only in the zinc-receiving group, along with Th2 cytokines (IL-10 and IL-4) being increased or remained elevated in both groups. Following stem cell transplantation, oral administration of a high dose of zinc (150 mg/day) increased thymic activity and output of new $\mathrm{CD} 4^{+}$naive $\mathrm{T}$ cells, which eventually helped in the prevention of Torque Teno virus reactivation (Iovino et al., 2018). Nonetheless, Provinciali et al. (1998) summarized that prolonged administration of zinc (400 $\mathrm{mg} /$ day) or zinc plus arginine $(4 \mathrm{~d} /$ day) in the elderly (age 64-100 years) people restored zinc concentrations in plasma, which was ineffective in stimulating or improving the antibody response or number of CD3, CD4, or CD8 lymphocytes following influenza vaccination.

\section{Selenium}

Selenium (a trace element) also exerts a range of important functions including antioxidant effects, various pleiotropic activities, and anti-inflammatory effects (Rayman, 2012). Selenium deficiency is found to be linked with cognitive impairment, poor immune response, and elevated risk of mortality, whereas an increased level of selenium or treatment with selenium has exhibited antiviral actions (Rayman, 2012). Broome et al. (2004) assessed whether an increased selenium administration (50-100 $\mu \mathrm{g} /$ day) ameliorated immune response in adults with a borderline concentration of selenium (Broome et al., 2004). Treatment with selenium elevated the plasma selenium levels, and also increased the activities of cytosolic glutathione peroxidase and lymphocyte phospholipid. Furthermore, selenium also increased the cellular immune responses (elevated level of IFN- $\gamma$ and other cytokines), along with an increased level of T-helper cells and earlier peak Tcell proliferation. Nonetheless, it was observed that humoral immune responses were not affected (Broome et al., 2004). Moreover, selenium treatment in participants also induced rapid poliovirus clearance.

\section{Copper}

Copper (another essential trace element) has a significant contribution in the differentiation and development of immune cells (Li et al., 2019). It has also been confirmed that copper exerted in vitro antiviral effects. Intracellular copper was found to regulate the life cycle of influenza virus (Rupp et al., 2017), while thujaplicin-copper chelates inhibited the replication of human influenza viruses (Miyamoto et al., 1998). In a study, Turnlund et al. (2004) determined the effects of chronic administration of copper on immune response, oxidative stress, and indices of copper status. These researchers observed that when copper was administered at a dose of $7.8 \mathrm{mg} /$ day, copper significantly increased the level of superoxide dismutase, benzylamine oxidase, and plasma ceruloplasmin activity as compared to $1.6 \mathrm{mg} /$ day dose, which further suggesting an enhancement in antioxidant status. Nonetheless, increased copper administration $(7.8 \mathrm{mg}$ /day) markedly decreased the proportion of antibody titer, serum IL-2R, and circulating neutrophils against the Beijing strain of influenza (Turnlund et al., 2004).

\section{Magnesium}

Magnesium (an essential mineral) has a significant contribution in regulating immune response via significantly affecting the $\mathrm{T}$ helper-B cell adherence, macrophage response to lymphokines, Immunoglobulin M (IgM) lymphocyte binding, adherence with immune cells, antibody-dependent cytolysis, and immunoglobulin synthesis (Liang et al., 2012). It has also been reported in in vivo and in-vitro studies that magnesium may have a contribution in the immune function against viral infections (Chaigne-Delalande et al., 2013).

\section{CONTROVERSIES REGARDING nCOVID-19 TREATMENTS}

Still now there is no specific antiviral drug to treat nCOVID-19, but some of the investigational drugs were found to be useful. Various drugs are being analyzed in vitro studies or clinical trials. Although ribavirin is a potent antiviral drug, its clinical effects are not clear and its side effects ought to be carefully considered. On the other hand, chloroquine has been studied in 15 interventional studies. Furthermore, in the Chinese Clinical Trial Registry, the derivatives of chloroquine were prospectively registered; and more studies are required to evaluate their antiviral effects and to estimate the recommended dose in nCOVID-19 patients (Zhang et al., 2020a). Along with antiviral drugs, glucocorticoids ought 
to be utilized carefully and in a timely manner in nCOVID19 patients. In addition to this, extracorporeal support need to be considered under strict contraindications and indications, otherwise, there will be numerous additional complications and also a waste of resources (Zhang et al., 2020a).

\section{FUTURE RESEARCH DIRECTIONS}

In order to manage the current nCOVID-19 outbreak, extensive measures are needed to be taken to lower the personto-person transmission of the virus. In addition to this, special efforts and attention are required to reduce or protect the susceptible populations such as elderly people, health care providers, and children. More studies are also essential to understand the mechanisms related to nCOVID19 pathogenesis. This better understanding will help the development of specific and effective therapies against SARS$\mathrm{CoV}-2$. Since the respiratory tract is mainly affected by SARS$\mathrm{CoV}-2$, thus special consideration is required to deliver the drug into the respiratory tract. More studies in animals and clinical trials on drug repositioning can also be considered to identify potential drugs to treat nCOVID-19.

\section{CONCLUSION}

Still there is no available specific drug or vaccine to treat nCOVID-19, thus effective preventative measures are

\section{REFERENCES}

Abu-Mouch, S., Fireman, Z., Jarchovsky, J., Zeina, A. R., and Assy, N. (2011). Vitamin D supplementation improves sustained virologic response in chronic hepatitis C (genotype 1)-naïve patients. World J. Gastroenterol. 17, 5184-5190. doi: 10.3748/wjg.v17.i47.5184

Acevedo-Murillo, J. A., García León, M. L., Firo-Reyes, V., SantiagoCordova, J. L., Gonzalez-Rodriguez, A. P., and Wong-Chew, R. M. (2019). Zinc supplementation promotes a Th1 response and improves clinical symptoms in fewer hours in children with pneumonia younger than 5 years old. A randomized controlled clinical trial. Front. Pediatr. 7:431. doi: 10.3389/fped.2019.00431

Adhikari, S. P., Meng, S., Wu, Y. J., Mao, Y. P., Ye, R. X., Wang, Q. Z., et al. (2020). Epidemiology, causes, clinical manifestation and diagnosis, prevention and control of coronavirus disease (COVID-19) during the early outbreak period: a scoping review. Infect. Dis. Poverty 9:29. doi: 10.1186/s40249-020-00646-X

Aglipay, M., Birken, C. S., Parkin, P. C., Loeb, M. B., Thorpe, K., Chen, Y., et al. (2017). Effect of high-dose vs standard-dose wintertime Vitamin D supplementation on viral upper respiratory tract infections in young healthy children. J. Am. Med. Assoc. 318, 245-254. doi: 10.1001/jama.2017.8708

Agostini, M. L., Andres, E. L., Sims, A. C., Graham, R. L., Sheahan, T. P., Lu, X., et al. (2018). Coronavirus susceptibility to the antiviral remdesivir (GS-5734) is mediated by the viral polymerase and the proofreading exoribonuclease. MBio 9, e00221-18. doi: 10.1128/mBio.00221-18

Andreone, P., Fiorino, S., Cursaro, C., Gramenzi, A., Margotti, M., Di Giammarino, L., et al. (2001). Vitamin E as treatment for chronic hepatitis B: results of a randomized controlled pilot trial. Antiviral Res. 49, 75-81. doi: 10.1016/S0166-3542(00)00141-8

Arabi, Y. M., Mandourah, Y., Al-Hameed, F., Sindi, A. A., Almekhlafi, G. A., Hussein, M. A., et al. (2018). Corticosteroid therapy for critically ill patients with middle east respiratory syndrome. Am. J. Respir. Crit. Care Med. 197, 757-767. doi: 10.1164/rccm.201706-1172OC recommended. Specific drugs are urgently required to inhibit the entry of the virus and subsequent replication to overcome this outbreak. Currently, as mentioned in this article, multiple investigational drugs and clinical trials are ongoing. The discovery of new drugs will ultimately enable us to better control this outbreak. Furthermore, in silico studies can also be considered to faster the drug development process. Finally, sharing findings or data will be effective to fight against nCOVID-19 globally.

\section{AUTHOR CONTRIBUTIONS}

MK and MU conceived the original idea and designed the outlines of the study and prepared the figures for the manuscript. MK wrote the initial draft of the manuscript. MU revised and improved the draft. $\mathrm{MH}, \mathrm{JA}, \mathrm{MA}, \mathrm{GA}, \mathrm{SB}$, MB-J, MA-D, and LA participated in the literature review of the manuscript. All authors have read and approved the final manuscript.

\section{ACKNOWLEDGMENTS}

This work was funded by the Deanship of Scientific Research at Princess Nourah bint Abdulrahman University, through the Fasttrack Research Funding Program. This work was supported by King Saud University, Deanship of Scientific Research, College of Science Research Center.
Arab-Zozani, M., Hassanipour, S., and Ghoddoosi-Nejad, D. J. (2020). Favipiravir for treating novel coronavirus (COVID-19) patients: protocol for a systematic review and meta-analysis of controlled trials. medRxiv. doi: 10.1101/2020.04.27.20081471. [Epub ahead of print].

Aranow, C. (2011). Vitamin D and the immune system. J. Investig. Med. 59, 881-886. doi: 10.2310/JIM.0b013e31821b8755

Assiri, A., Al-Tawfiq, J. A., Al-Rabeeah, A. A., Al-Rabiah, F. A., Al-Hajjar, S., Al-Barrak, A., et al. (2013). Epidemiological, demographic, and clinical characteristics of 47 cases of Middle East respiratory syndrome coronavirus disease from Saudi Arabia: a descriptive study. Lancet Infect. Dis. 13, 752-761. doi: 10.1016/S1473-3099(13)70204-4

Auyeung, T. W., Lee, J. S. W., Lai, W. K., Choi, C. H., Lee, H. K., Lee, J. S., et al. (2005). The use of corticosteroid as treatment in SARS was associated with adverse outcomes: a retrospective cohort study. J. Infect. 51, 98-102. doi: 10.1016/j.jinf.2004.09.008

Bacharier, L. B., Guilbert, T. W., Mauger, D. T., Boehmer, S., Beigelman, A., Fitzpatrick, A. M., et al. (2015). Early Administration of azithromycin and prevention of severe lower respiratory tract illnesses in preschool children with a history of such illnesses a randomized clinical trial. J. Am. Med. Assoc. 314, 2034-2044. doi: 10.1001/jama.2015.13896

Bae, S., Kim, M.-C., Kim, J. Y., Cha, H.-H., Lim, J. S., Jung, J., et al. (2020). Effectiveness of surgical and cotton masks in blocking SARS-CoV-2: a controlled comparison in 4 patients. Ann. Intern. Med. 6, M20-M1342. doi: $10.7326 / \mathrm{m} 20-1342$

Bao, J., Wang, Z., Yu, C., and Li, X. (2016). The influence of temperature on mortality and its lag effect: a study in four Chinese cities with different latitudes. BMC Public Health 16:375. doi: 10.1186/s12889-016-3031-z

Baron, S. A., Devaux, C., Colson, P., Raoult, D., and Rolain, J. M. (2020). Teicoplanin: an alternative drug for the treatment of COVID-19? Int. J. Antimicrob. Agents 55:105944. doi: 10.1016/j.ijantimicag.2020.105944

Beigel, J. H., Nam, H. H., Adams, P. L., Krafft, A., Ince, W. L., El-Kamary, S. S., et al. (2019). Advances in respiratory virus therapeutics - a meeting 
report from the 6th isirv antiviral group conference. Antiviral Res. 167, 45-67. doi: 10.1016/j.antiviral.2019.04.006

Bekerman, E., Neveu, G., Shulla, A., Brannan, J., Pu, S. Y., Wang, S., et al. (2017). Anticancer kinase inhibitors impair intracellular viral trafficking and exert broad-spectrum antiviral effects. J. Clin. Invest. 127, 1338-1352. doi: 10.1172/JCI89857

Belouzard, S., Chu, V. C., and Whittaker, G. R. (2009). Activation of the SARS coronavirus spike protein via sequential proteolytic cleavage at two distinct sites. Proc. Natl. Acad. Sci. U.S.A. 106, 5871-5876. doi: 10.1073/pnas.0809524106

Bogoch, I. I., Watts, A., Thomas-Bachli, A., Huber, C., Kraemer, M. U. G., and Khan, K. (2020). Pneumonia of unknown aetiology in Wuhan, China: potential for international spread via commercial air travel. J. Travel Med. 27:taaa008. doi: $10.1093 / \mathrm{jtm} / \mathrm{taaa} 008$

Borchgrevink, C. P., Cha, J. M., and Kim, S. H. (2013). Hand washing practices in a college town environment. J. Environ. Health 75, 18-24. Available online at: https://europepmc.org/article/med/23621052

Boriskin, Y., Leneva, I., Pecheur, E.-I., and Polyak, S. (2008). Arbidol: a broadspectrum antiviral compound that blocks viral fusion. Curr. Med. Chem. 15, 997-1005. doi: 10.2174/092986708784049658

Broome, C. S., McArdle, F., Kyle, J. A. M., Andrews, F., Lowe, N. M., Hart, C. A., et al. (2004). An increase in selenium intake improves immune function and poliovirus handling in adults with marginal selenium status. Am. J. Clin. Nutr. 80, 154-162. doi: $10.1093 /$ ajcn/80.1.154

Brown, A. J., Won, J. J., Graham, R. L., Dinnon, K. H., Sims, A. C., Feng, J. Y., et al. (2019). Broad spectrum antiviral remdesivir inhibits human endemic and zoonotic deltacoronaviruses with a highly divergent RNA dependent RNA polymerase. Antiviral Res. 169:104541. doi: 10.1016/j.antiviral.2019.104541

Cai, Q. C., Lu, J., Xu, Q. F., Guo, Q., Xu, D. Z., Sun, Q. W., et al. (2007). Influence of meteorological factors and air pollution on the outbreak of severe acute respiratory syndrome. Public Health 121, 258-265. doi: 10.1016/j.puhe.2006.09.023

Caly, L., Druce, J. D., Catton, M. G., Jans, D. A., and Wagstaff, K. M. (2020). The FDA-approved drug ivermectin inhibits the replication of SARS-CoV-2 in vitro. Antiviral Res. 178:104787. doi: 10.1016/j.antiviral.2020.104787

Caly, L., Wagstaff, K. M., and Jans, D. A. (2012). Nuclear trafficking of proteins from RNA viruses: potential target for antivirals? Antiviral Res. 95, 202-206. doi: 10.1016/j.antiviral.2012.06.008

Cameron, M. J., Bermejo-Martin, J. F., Danesh, A., Muller, M. P., and Kelvin, D. J. (2008). Human immunopathogenesis of severe acute respiratory syndrome (SARS). Virus Res. 133, 13-19. doi: 10.1016/j.virusres.2007.02.014

Cao, B., Wang, Y., Wen, D., Liu, W., Wang, J., Fan, G., et al. (2020). A Trial of lopinavir-ritonavir in adults hospitalized with severe covid-19. N. Engl. J. Med. 382, 1787-1799. doi: 10.1056/nejmoa2001282

CDC (2020a). Cases in the U.S. Available online at: https://www.cdc.gov/ coronavirus/2019-ncov/cases-updates/cases-in- us.html?CDC_AA_refVal= https\%3A\%2F\%2Fwww.cdc.gov\%2Fcoronavirus\%2F2019-ncov\%2Fcasesupdates\%2Fsummary.html (accessed June 7, 2020a).

CDC (2020b). Infection Control Guidance for Healthcare Professionals about Coronavirus (COVID-19). Available online at: https://www.cdc.gov/ coronavirus/2019-ncov/hcp/infection-control.html (accessed June 7, 2020b).

Chaigne-Delalande, B., Li, F. Y., O'Connor, G. M., Lukacs, M. J., Jiang, P., Zheng, L., et al. (2013). Mg2+ regulates cytotoxic functions of NK and CD8 T cells in chronic EBV infection through NKG2D. Science 341, 186-191. doi: $10.1126 /$ science. 1240094

Chan, J. F.-W., Yao, Y., Yeung, M.-L., Deng, W., Bao, L., Jia, L., et al. (2015). Treatment with lopinavir/ritonavir or interferon- $\beta 1 \mathrm{~b}$ improves outcome of MERS-CoV infection in a nonhuman primate model of common marmoset. J. Infect. Dis. 212, 1904-1913. doi: 10.1093/infdis/jiv392

Chan, J. F. W., Lau, S. K. P., and Woo, P. C. Y. (2013). The emerging novel middle east respiratory syndrome coronavirus: the "knowns" and "unknowns." J. Formos. Med. Assoc. 112, 372-381. doi: 10.1016/j.jfma.2013.05.010

Chan, K. H., Peiris, J. S. M., Lam, S. Y., Poon, L. L. M., Yuen, K. Y., and Seto, W. H. (2011). The effects of temperature and relative humidity on the viability of the SARS coronavirus. Adv. Virol. 2011:734690. doi: 10.1155/2011/ 734690

Channappanavar, R., Fehr, A. R., Vijay, R., Mack, M., Zhao, J., Meyerholz, D. K., et al. (2016). Dysregulated type $\mathrm{i}$ interferon and inflammatory monocyte-macrophage responses cause lethal pneumonia in SARS-CoVinfected mice. Cell Host Microbe 19, 181-193. doi: 10.1016/j.chom.2016.01.007

Channappanavar, R., Fehr, A. R., Zheng, J., Wohlford-Lenane, C., Abrahante, J. E., Mack, M., et al. (2019). IFN-I response timing relative to virus replication determines MERS coronavirus infection outcomes. J. Clin. Invest. 129, 3625-3639. doi: 10.1172/JCI126363

Channappanavar, R., and Perlman, S. (2017). Pathogenic human coronavirus infections: causes and consequences of cytokine storm and immunopathology. Semin. Immunopathol. 39, 529-539. doi: 10.1007/s00281-017-0629-x

Chen, L., Xiong, J., Bao, L., and Shi, Y. (2020a). Convalescent plasma as a potential therapy for COVID-19. Lancet Infect. Dis. 20, 398-400. doi: 10.1016/S1473-3099(20)30141-9

Chen, R. C., Tang, X. P., Tan, S. Y., Liang, B. L., Wan, Z. Y., Fang, J. Q., et al. (2006a). Treatment of severe acute respiratory syndrome with glucosteroids: the Guangzhou experience. Chest 129, 1441-1452. doi: 10.1378/chest.129.6.1441

Chen, T., Wu, D., Chen, H., Yan, W., Yang, D., Chen, G., et al. (2020b). Clinical characteristics of 113 deceased patients with coronavirus disease 2019: retrospective study. BMJ 368: m1091. doi: 10.1136/bmj.m1091

Chen, Y. M. A., Liang, S. Y., Shih, Y. P., Chen, C. Y., Lee, Y. M., Chang, L., et al. (2006b). Epidemiological and genetic correlates of severe acute respiratory syndrome coronavirus infection in the hospital with the highest nosocomial infection rate in Taiwan in 2003. J. Clin. Microbiol. 44, 359-365. doi: 10.1128/JCM.44.2.359-365.2006

Chou, C. C., Shen, C. F., Chen, S. J., Chen, H. M., Wang, Y. C., Chang, W. S., et al. (2019). Recommendations and guidelines for the treatment of pneumonia in Taiwan. J. Microbiol. Immunol. Infect. 52, 172-199. doi: 10.1016/j.jmii.2018.11.004

ClinicalTrials.gov (2020a). Cohort Multiple Randomized Controlled Trials Openlabel of Immune Modulatory Drugs and Other Treatments in COVID-19 Patients - Sarilumab Trial - CORIMUNO-19 - SARI. Available online at: https:// clinicaltrials.gov/ct2/show/NCT04324073?load=cart (accessed June 4, 2020)

ClinicalTrials.gov (2020b). Eculizumab (Soliris) in Covid-19 Infected Patients. Available online at: https://clinicaltrials.gov/ct2/show/NCT04288713 (accessed June 4, 2020).

ClinicalTrials.gov (2020c). Efficacy and Safety of Emapalumab and Anakinra in Reducing Hyperinflammation and Respiratory Distress in Patients With COVID-19 Infection. Available online at: https://clinicaltrials.gov/ct2/show/ NCT04324021 (accessed June 4, 2020).

ClinicalTrials.gov (2020d). Evaluation of the Efficacy and Safety of Sarilumab in Hospitalized Patients With COVID-19. Available online at: https://clinicaltrials. gov/ct2/show/NCT04315298 (accessed June 4, 2020).

ClinicalTrials.gov (2020e). Study to Evaluate the Safety and Antiviral Activity of Remdesivir (GS-5734TM) in Participants With Moderate Coronavirus Disease (COVID-19) Compared to Standard of Care Treatment. Available online at: https://clinicaltrials.gov/ct2/show/NCT04292730 (accessed June 7, 2020).

ClinicalTrials.gov (2020f). Treatment of Moderate to Severe Coronavirus Disease (COVID-19) in Hospitalized Patients. Available online at: https://clinicaltrials. gov/ct2/show/NCT04321993 (accessed June 4, 2020).

Cockrell, A. S., Yount, B. L., Scobey, T., Jensen, K., Douglas, M., Beall, A., et al. (2016). A mouse model for MERS coronavirus-induced acute respiratory distress syndrome. Nat. Microbiol. 2, 1-11. doi: 10.1038/nmicrobiol. 2016.226

Cortegiani, A., Ingoglia, G., Ippolito, M., Giarratano, A., and Einav, S. (2020). A systematic review on the efficacy and safety of chloroquine for the treatment of COVID-19. J. Crit. Care. 57, 279-283. doi: 10.1016/j.jcrc.2020.03.005

Cowling, B. J., Chan, K. H., Fang, V. J., Cheng, C. K. Y., Fung, R. O. P., Wai, W., et al. (2009). Facemasks and hand hygiene to prevent influenza transmission in households: a cluster randomized trial. Ann. Intern. Med. 151, 437-446. doi: 10.7326/0003-4819-151-7-200910060-00142

Cui, Y., Zhang, Z.-F., Froines, J., Zhao, J., Wang, H., Yu, S.-Z., et al. (2003). Air pollution and case fatality of SARS in the people's republic of China: an ecologic study. Environ. Heal. 2:15. doi: 10.1186/1476-069x-2-15

Cunningham, A. C., Goh, H. P., and Koh, D. (2020). Treatment of COVID-19: Old tricks for new challenges. Crit. Care 24, 1-2. doi: 10.1186/s13054-020-2818-6

D’Amato, M., Molino, A., Calabrese, G., Cecchi, L., Annesi-Maesano, I. and D'Amato, G. (2018). The impact of cold on the respiratory tract and its consequences to respiratory health. Clin. Transl. Allergy 8:20. doi: 10.1186/s13601-018-0208-9 
Day, M. (2020). Covid-19: ibuprofen should not be used for managing symptoms, say doctors and scientists. BMJ 368:m1086. doi: 10.1136/bmj.m1086

de Wit, E., Feldmann, F., Cronin, J., Jordan, R., Okumura, A., Thomas, T., et al. (2020). Prophylactic and therapeutic remdesivir (GS-5734) treatment in the rhesus macaque model of MERS-CoV infection. Proc. Natl. Acad. Sci. U.S.A. 117, 6771-6776. doi: 10.1073/pnas.1922083117

de Wit, E., van Doremalen, N., Falzarano, D., and Munster, V. J. (2016). SARS and MERS: recent insights into emerging coronaviruses. Nat. Rev. Microbiol. 14, 523-534. doi: 10.1038/nrmicro.2016.81

Deng, L., Li, C., Zeng, Q., Liu, X., Li, X., Zhang, H., et al. (2020). Arbidol combined with LPV/r versus LPV/r alone against corona virus disease 2019: a retrospective cohort study. J. Infect. 81, e1-e5. doi: 10.1016/j.jinf.2020.03.002

Fan, Y. Y., Huang, Z. T., Li, L., Wu, M. H., Yu, T., Koup, R. A., et al. (2009). Characterization of SARS-CoV-specific memory T cells from recovered individuals 4 years after infection. Arch. Virol. 154, 1093-1099. doi: 10.1007/s00705-009-0409-6

Fang, L., Karakiulakis, G., and Roth, M. (2020). Are patients with hypertension and diabetes mellitus at increased risk for COVID-19 infection? Lancet Respir. Med. 8:e21. doi: 10.1016/S2213-2600(20)30116-8

Favalli, E. G., Ingegnoli, F., De Lucia, O., Cincinelli, G., Cimaz, R., and Caporali, R. (2020). COVID-19 infection and rheumatoid arthritis: faraway, so close! Autoimmun. Rev. 19:102523. doi: 10.1016/j.autrev.2020.102523

FDA (2020). Request for Emergency Use Authorization For Use of Chloroquine Phosphate or Hydroxychloroquine Sulfate Supplied From the Strategic National Stockpile for Treatment of, 019 Coronavirus Disease. Available online at: https:// www.fda.gov/media/136534/download (accessed June 7, 2020).

Fedson, D. S. (2016). Treating the host response to emerging virus diseases: lessons learned from sepsis, pneumonia, influenza and Ebola. Ann. Transl. Med. 4:421. doi: $10.21037 / 12396$

Fedson, D. S., Opal, S. M., and Rordam, O. M. (2020). Hiding in plain sight: an approach to treating patients with severe covid-19 infection. MBio 11, e00398-20. doi: 10.1128/mBio.00398-20

Fehr, A. R., and Perlman, S. (2015). "Coronaviruses: an overview of their replication and pathogenesis," in Coronaviruses: Methods and Protocols, eds M. Helena, B. Erica, and B. Paul (New York, NY: Springer), 1-23. doi: 10.1007/978-1-4939-2438-7_1. Available online at: https://www.springer. com/gp/book/9781493924370

Fiorino, S., Bacchi-Reggiani, M. L., Leandri, P., Loggi, E., and Andreone, P. (2017). Vitamin $\mathrm{E}$ for the treatment of children with hepatitis B e antigen-positive chronic hepatitis: a systematic review and meta-analysis. World J. Hepatol. 9, 333-342. doi: 10.4254/wjh.v9.i6.333

Fujifilm (2020). Global Fujifilm accelerates production of its influenza antiviral drug “Avigan ( Tablet” for COVID-19. Available online at: https://www.fujifilm.com/ news/n200415.html (accessed June 7, 2020).

Fung, T. S., and Liu, D. X. (2019). Human coronavirus: hostpathogen interaction. Annu. Rev. Microbiol. 73, 529-557. doi: 10.1146/annurev-micro-020518-115759

Gamiño-Arroyo, A. E., Guerrero, M. L., McCarthy, S., Ramírez-Venegas, A., Llamosas-Gallardo, B., Galindo-Fraga, A., et al. (2019). Efficacy and safety of nitazoxanide in addition to standard of care for the treatment of severe acute respiratory illness. Clin. Infect. Dis. 69, 1903-1911. doi: 10.1093/cid/ciz100

Gao, Z., Xu, Y., Sun, C., Wang, X., Guo, Y., Qiu, S., et al. (2020). A systematic review of asymptomatic infections with COVID-19. J. Microbiol. Immunol. Infect. doi: 10.1016/j.jmii.2020.05.001. [Epub ahead of print].

Gautret, P., Lagier, J.-C., Parola, P., Hoang, V. T., Meddeb, L., Mailhe, M., et al. (2020). Hydroxychloroquine and azithromycin as a treatment of COVID-19: results of an open-label non-randomized clinical trial. Int. J. Antimicrob. Agents doi: 10.1016/j.ijantimicag.2020.105949. [Epub ahead of print].

Ginde, A. A., Blatchford, P., Breese, K., Zarrabi, L., Linnebur, S. A., Wallace, J. I., et al. (2017). High-dose monthly vitamin D for prevention of acute respiratory infection in older long-term care residents: a randomized clinical trial. J. Am. Geriatr. Soc. 65, 496-503. doi: 10.1111/jgs.14679

Glowacka, I., Bertram, S., Muller, M. A., Allen, P., Soilleux, E., Pfefferle, S., et al. (2011). Evidence that TMPRSS2 activates the severe acute respiratory syndrome coronavirus spike protein for membrane fusion and reduces viral control by the humoral immune response. J. Virol. 85, 4122-4134. doi: 10.1128/jvi. 02232-10
Goncalves-Mendes, N., Talvas, J., Dual,é, C., Guttmann, A., Corbin, V., Marceau, G., et al. (2019). Impact of vitamin D supplementation on influenza vaccine response and immune functions in deficient elderly persons: a randomized placebo-controlled trial. Front. Immunol. 10:65. doi: 10.3389/fimmu.2019.00065

Graham Carlos, W., Dela Cruz, C. S., Cao, B., Pasnick, S., and Jamil, S. (2020). Novel wuhan (2019-NCoV) coronavirus. Am. J. Respir. Crit. Care Med. 201, P7-P8. doi: 10.1164/rccm.2014P7

Gralinski, L. E., and Menachery, V. D. (2020). Return of the coronavirus: 2019nCoV. Viruses 12:135. doi: 10.3390/v12020135

Gralinski, L. E., Sheahan, T. P., Morrison, T. E., Menachery, V. D., Jensen, K., Leist, S. R., et al. (2018). Complement activation contributes to severe acute respiratory syndrome coronavirus pathogenesis. MBio 9:e01753-18. doi: 10.1128/mBio.01753-18

Grillet, F., Behr, J., Calame, P., Aubry, S., and Delabrousse, E. (2020). Acute pulmonary embolism associated with COVID-19 pneumonia detected by pulmonary CT angiography. Radiology 23:201544. doi: 10.1148/radiol.2020201544

Guan, W., Ni, Z., Hu, Y., Liang, W., Ou, C., He, J., et al. (2020). Clinical characteristics of coronavirus disease 2019 in China. N. Engl. J. Med. 382, 1708-1720. doi: 10.1056/NEJMoa2002032

Haffizulla, J., Hartman, A., Hoppers, M., Resnick, H., Samudrala, S., Ginocchio, C., et al. (2014). Effect of nitazoxanide in adults and adolescents with acute uncomplicated influenza: a double-blind, randomised, placebo-controlled, phase $2 \mathrm{~b} / 3$ trial. Lancet Infect. Dis. 14, 609-618. doi: 10.1016/S1473-3099(14)70717-0

Hajat, S., and Kosatky, T. (2010). Heat-related mortality: a review and exploration of heterogeneity. J. Epidemiol. Community Health 64, 753-760. doi: 10.1136/jech.2009.087999

Hajeer, A. H., Balkhy, H., Johani, S., Yousef, M. Z., and Arabi, Y. (2016). Association of human leukocyte antigen class II alleles with severe middle east respiratory syndrome-coronavirus infection. Ann. Thorac. Med. 11, 211-213. doi: 10.4103/1817-1737.185756

Hemilä, H., and Chalker, E. (2013). Vitamin C for preventing and treating the common cold. Cochrane Database Syst. Rev. 2013:CD000980. doi: 10.1002/14651858.CD000980.pub4

Hemilä, H., and Kaprio, J. (2008). Vitamin E supplementation and pneumonia risk in males who initiated smoking at an early age: effect modification by body weight and dietary vitamin C. Nutr. J. 7:33. doi: 10.1186/1475-2891-7-33

Holshue, M. L., DeBolt, C., Lindquist, S., Lofy, K. H., Wiesman, J., Bruce, H., et al. (2020). First case of 2019 novel coronavirus in the united states. N. Engl. J. Med. 382, 929-936. doi: 10.1056/NEJMoa2001191

Huang, C., Wang, Y., Li, X., Ren, L., Zhao, J., Hu, Y., et al. (2020). Clinical features of patients infected with 2019 novel coronavirus in Wuhan, China. Lancet 395, 497-506. doi: 10.1016/S0140-6736(20)30183-5

Huang, Z., Liu, Y., Qi, G., Brand, D., and Zheng, S. (2018). Role of Vitamin A in the immune system. J. Clin. Med. 7:258. doi: 10.3390/jcm7090258

InvivoGen (2020). Spotlight on COVID-19: Infection. Available online at: https:// www.invivogen.com/spotlight-covid-19-infection (accessed June 7, 2020).

Iovino, L., Mazziotta, F., Carulli, G., Guerrini, F., Morganti, R., Mazzotti, V., et al. (2018). High-dose zinc oral supplementation after stem cell transplantation causes an increase of TRECs and CD4+ naïve lymphocytes and prevents TTV reactivation. Leuk. Res. 70, 20-24. doi: 10.1016/j.leukres.2018.04.016

Ip, W. K. E., Chan, K. H., Law, H. K. W., Tso, G. H. W., Kong, E. K. P., Wong, W. H. S., et al. (2005). Mannose-binding lectin in severe acute respiratory syndrome coronavirus infection. J. Infect. Dis. 191, 1697-1704. doi: 10.1086/ 429631

Jaakkola, K., Saukkoriipi, A., Jokelainen, J., Juvonen, R., Kauppila, J., Vainio, O., et al. (2014). Decline in temperature and humidity increases the occurrence of influenza in cold climate. Environ. Heal. A Glob. Access Sci. Source 13:22. doi: 10.1186/1476-069X-13-22

Jean, S.-S., Chang, Y.-C., Lin, W.-C., Lee, W.-S., Hsueh, P.-R., and Hsu, C.W. (2020a). Epidemiology, treatment, and prevention of nosocomial bacterial pneumonia. J. Clin. Med. 9:275. doi: 10.3390/jcm9010275

Jean, S.-S., Lee, P.-I., and Hsueh, P.-R. (2020b). Treatment options for COVID19: the reality and challenges. J. Microbiol. Immunol. Infect. 53, 436-443. doi: $10.1016 /$ j.jmii.2020.03.034 
Jolliffe, D. A., Griffiths, C. J., and Martineau, A. R. (2013). Vitamin D in the prevention of acute respiratory infection: systematic review of clinical studies. J. Steroid Biochem. Mol. Biol. 136, 321-329. doi: 10.1016/j.jsbmb.2012.11.017

Kaiser Health News (2020). CDC Coronavirus Testing Decision Likely To Haunt Nation For Months To Come. Available online at: https://khn.org/news/cdccoronavirus-testing-decision-likely-to-haunt-nation-for-months-to-come/ (accessed June 7, 2020).

Kampf, G., Todt, D., Pfaender, S., and Steinmann, E. (2020). Persistence of coronaviruses on inanimate surfaces and their inactivation with biocidal agents. J. Hosp. Infect. 104, 246-251. doi: 10.1016/j.jhin.2020.01.022

Kaneko, A. (2013). Tocilizumab in rheumatoid arthritis: efficacy, safety and its place in therapy. Ther. Adv. Chronic Dis. 4, 15-21. doi: $10.1177 / 2040622312466908$

Kawase, M., Shirato, K., van der Hoek, L., Taguchi, F., and Matsuyama, S. (2012). Simultaneous treatment of human bronchial epithelial cells with serine and cysteine protease inhibitors prevents severe acute respiratory syndrome coronavirus entry. J. Virol. 86, 6537-6545. doi: 10.1128/jvi.00094-12

Keicho, N., Itoyama, S., Kashiwase, K., Phi, N. C., Long, H. T., Ha, L. D., et al. (2009). Association of human leukocyte antigen class II alleles with severe acute respiratory syndrome in the vietnamese population. Hum. Immunol. 70, 527-531. doi: 10.1016/j.humimm.2009.05.006

Kim, Y., Kim, H., Bae, S., Choi, J., Lim, S. Y., Lee, N., et al. (2013). Vitamin C is an essential factor on the anti-viral immune responses through the production of interferon- $\alpha / \beta$ at the initial stage of influenza a virus (H3N2) infection. Immune Netw. 13:70. doi: 10.4110/in.2013.13.2.70

Klok, F. A., Kruip, M. J. H. A., van der Meer, N. J. M., Arbous, M. S., Gommers, D. A. M. P. J., Kant, K. M., et al. (2020). Incidence of thrombotic complications in critically ill ICU patients with COVID-19. Thromb. Res. 191, 145-147. doi: 10.1016/j.thromres.2020.04.013

Ko, W. C., Rolain, J. M., Lee, N. Y., Chen, P. L., Huang, C. T., Lee, P. I., et al. (2020). Arguments in favour of remdesivir for treating SARS-CoV-2 infections. Int. J. Antimicrob. Agents 55:105933. doi: 10.1016/j.ijantimicag.2020.105933

Kuba, K., Imai, Y., Ohto-Nakanishi, T., and Penninger, J. M. (2010). Trilogy of ACE2: a peptidase in the renin-angiotensin system, a SARS receptor, and a partner for amino acid transporters. Pharmacol. Ther. 128, 119-128. doi: 10.1016/j.pharmthera.2010.06.003

Kudo, E., Song, E., Yockey, L. J., Rakib, T., Wong, P. W., Homer, R. J., et al. (2019). Low ambient humidity impairs barrier function and innate resistance against influenza infection. Proc. Natl. Acad. Sci. U.S.A. 166, 10905-10910. doi: 10.1073/pnas.1902840116

Kumar, S., Nyodu, R., Maurya, V. K., and Saxena, S. K. (2020). "Host immune response and immunobiology of human SARS-CoV-2 infection," in Coronavirus Disease 2019 (COVID-19), ed S. K. Saxena (Singapore: Springer), 43-53. doi: 10.1007/978-981-15-4814-7_5. Available online at: https://link. springer.com/book/10.1007/978-981-15-4814-7\#about

Lauring, A. S., and Andino, R. (2010). Quasispecies theory and the behavior of RNA viruses. PLoS Pathog. 6:e1001005. doi: 10.1371/journal.ppat.1001005

Lee, N., Hui, D., Wu, A., Chan, P., Cameron, P., Joynt, G. M., et al. (2003). A major outbreak of severe acute respiratory syndrome in Hong Kong. N. Engl. J. Med. 348, 1986-1994. doi: 10.1056/NEJMoa030685

Lei, J., Li, J., Li, X., and Qi, X. (2020). CT imaging of the 2019 novel coronavirus (2019-nCoV) pneumonia. Radiology 295, 18-18. doi: 10.1148/radiol.2020200236

Li, C., Li, Y., and Ding, C. (2019). The role of copper homeostasis at the host-pathogen axis: from bacteria to fungi. Int. J. Mol. Sci. 20:175. doi: 10.3390/ijms20010175

Li, G., Chen, X., and Xu, A. (2003a). Profile of specific antibodies to the SARS-associated coronavirus [6]. N. Engl. J. Med. 349, 508-509. doi: $10.1056 /$ NEJM200307313490520

Li, G., and De Clercq, E. (2020). Therapeutic options for the 2019 novel coronavirus (2019-nCoV). Nat. Rev. Drug Discov. 19, 149-150. doi: $10.1038 / \mathrm{d} 41573-020-00016-0$

Li, H., Liu, Z., and Ge, J. (2020a). Scientific research progress of COVID-19/ SARS-CoV-2 in the first five months. J. Cell. Mol. Med. 24, 6558-6570. doi: $10.1111 /$ jcmm. 15364

Li, Q., Guan, X., Wu, P., Wang, X., Zhou, L., Tong, Y., et al. (2020b). Early transmission dynamics in Wuhan, China, of novel coronavirus-infected pneumonia. N. Engl. J. Med. 382, 1199-1207. doi: 10.1056/NEJMoa2001316
Li, W., Moore, M. J., Vasilieva, N., Sui, J., Wong, S. K., Berne, M. A., et al. (2003b). Angiotensin-converting enzyme 2 is a functional receptor for the SARS coronavirus. Nature 426, 450-454. doi: 10.1038/nature02145

Liang, R. Y., Wu, W., Huang, J., Jiang, S. P., and Lin, Y. (2012). Magnesium affects the cytokine secretion of CD4+ T lymphocytes in acute asthma. J. Asthma 49, 1012-1015. doi: 10.3109/02770903.2012.739240

Lin, K., Fong, D. Y. T., Zhu, B., and Karlberg, J. (2006). Environmental factors on the SARS epidemic: air temperature, passage of time and multiplicative effect of hospital infection. Epidemiol. Infect. 134, 223-230. doi: $10.1017 /$ S0950268805005054

Liu, J., Wu, P., Gao, F., Qi, J., Kawana-Tachikawa, A., Xie, J., et al. (2010). Novel immunodominant peptide presentation strategy: a featured HLA-A*2402restricted cytotoxic T-lymphocyte epitope stabilized by intrachain hydrogen bonds from severe acute respiratory syndrome coronavirus nucleocapsid protein. J. Virol. 84, 11849-11857. doi: 10.1128/jvi.01464-10

Liu, T., Hu, J., Kang, M., Lin, L., Zhong, H., Xiao, J., et al. (2020). Time-varying transmission dynamics of novel coronavirus pneumonia in China. bioRxiv. doi: 10.1101/2020.01.25.919787. [Epub ahead of print].

Lowen, A. C., and Steel, J. (2014). Roles of humidity and temperature in shaping influenza seasonality. J. Virol. 88, 7692-7695. doi: 10.1128/jvi.03544-13

Lu, H., Stratton, C. W., and Tang, Y. W. (2020). Outbreak of pneumonia of unknown etiology in Wuhan, China: the mystery and the miracle. J. Med. Virol. 92, 401-402. doi: $10.1002 / j m v .25678$

Luo, H., Tang, Q., ling, Shang, Y., xi, Liang, S., bing, Yang, M., Robinson, N., et al. (2020). Can Chinese medicine be used for prevention of corona virus disease 2019 (COVID-19)? A review of historical classics, research evidence and current prevention programs. Chin. J. Integr. Med. 26, 243-250. doi: 10.1007/s11655-020-3192-6

Ma, Y., Zhao, Y., Liu, J., He, X., Wang, B., Fu, S., et al. (2020). Effects of temperature variation and humidity on the death of COVID-19 in Wuhan, China. Sci. Total Environ. 724:138226. doi: 10.1016/j.scitotenv.2020.138226

Madrid, P. B., Panchal, R. G., Warren, T. K., Shurtleff, A. C., Endsley, A. N., Green, C. E., et al. (2016). Evaluation of ebola virus inhibitors for drug repurposing. ACS Infect. Dis. 1, 317-326. doi: 10.1021/acsinfecdis.5b00030

Martinez, M. A. (2020). Compounds with therapeutic potential against novel respiratory 2019 coronavirus. Antimicrob. Agents Chemother. 64 doi: 10.1128/aac.00399-20

Mayence, A., and Vanden Eynde, J. (2019). Baricitinib: a 2018 novel FDAapproved small molecule inhibiting janus kinases. Pharmaceuticals 12:37. doi: $10.3390 /$ ph12010037

McCreary, E. K., and Pogue, J. M. (2020). Coronavirus disease 2019 treatment: a review of early and emerging options. Open Forum Infect. Dis. 7:ofaa105. doi: 10.1093/ofid/ofaa105

Menachery, V. D., Schäfer, A., Burnum-Johnson, K. E., Mitchell, H. D., Eisfeld, A. J., Walters, K. B., et al. (2018). MERS-CoV and H5N1 influenza virus antagonize antigen presentation by altering the epigenetic landscape. Proc. Natl. Acad. Sci. U.S.A. 115, E1012-E1021. doi: 10.1073/pnas.1706928115

Meydani, S. N., Leka, L. S., Fine, B. C., Dallal, G. E., Keusch, G. T., Singh, M. F., et al. (2004). Vitamin E and respiratory tract infections in elderly nursing home residents: a randomized controlled trial. J. Am. Med. Assoc. 292, 828-836. doi: 10.1001/jama.292.7.828

Mille, J. K., and Whittaker, G. R. (2014). Host cell entry of middle east respiratory syndrome coronavirus after two-step, furin-mediated activation of the spike protein. Proc. Natl. Acad. Sci. U.S.A. 111, 15214-15219. doi: 10.1073/pnas.1407087111

Min, C. K., Cheon, S., Ha, N. Y., Sohn, K. M., Kim, Y., Aigerim, A., et al. (2016). Comparative and kinetic analysis of viral shedding and immunological responses in MERS patients representing a broad spectrum of disease severity. Sci. Rep. 6:25359. doi: 10.1038/srep25359

Miyamoto, D., Kusagaya, Y., Endo, N., Sometani, A., Takeo, S., Suzuki, T., et al. (1998). Thujaplicin-copper chelates inhibit replication of human influenza viruses. Antiviral Res. 39, 89-100. doi: 10.1016/S0166-3542(98)00034-5

Monlezun, D. J., Bittner, E. A., Christopher, K. B., Camargo, C. A., and Quraishi, S. A. (2015). Vitamin D status and acute respiratory infection: cross sectional results from the United States national health and nutrition examination survey, 2001-2006. Nutrients 7, 1933-1944. doi: 10.3390/nu7031933

Moriguchi, S., and Muraga, M. (2000). Vitamin E and immunity. Vitam. Horm. 59, 305-336. doi: 10.1016/s0083-6729(00)59011-6 
Mulangu, S., Dodd, L. E., Davey, R. T., Tshiani Mbaya, O., Proschan, M., Mukadi, D., et al. (2019). A randomized, controlled trial of ebola virus disease therapeutics. N. Engl. J. Med. 381, 2293-2303. doi: 10.1056/NEJMoa1910993

Mungroo, M. R., Khan, N. A., and Siddiqui, R. (2020). Novel coronavirus: current understanding of clinical features, diagnosis, pathogenesis, and treatment options. Pathogens 9:297. doi: 10.3390/pathogens9040297

Niemeyer, D., Zillinger, T., Muth, D., Zielecki, F., Horvath, G., Suliman, T., et al. (2013). Middle east respiratory syndrome coronavirus accessory protein $4 \mathrm{a}$ is a type I interferon antagonist. J. Virol. 87, 12489-12495. doi: 10.1128/jvi. 01845-13

Nimer, A., and Mouch, A. (2012). Vitamin D improves viral response in hepatitis C genotype 2-3 naïve patients. World J. Gastroenterol. 18, 800-805. doi: 10.3748/wjg.v18.i8.800

NPR (2020). Coronavirus Has Now Spread To All Regions Of Mainland China. Available online at: https://www.npr.org/sections/goatsandsoda/2020/01/30/ $801142924 /$ coronavirus-has-now-spread-to-all-regions-of-mainland-china (accessed June 7, 2020).

Ogawa, M., and Morisada, A. (2002). Novel mode of action of ribavirin

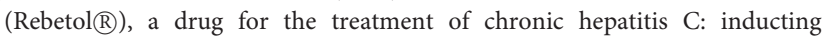
the mutation of RNA viruses. Folia Pharmacol. Jpn. 120, 398-408. doi: $10.1254 /$ fpj. 120.398

Park, J. E., Son, W. S., Ryu, Y., Choi, S. B., Kwon, O., and Ahn, I. (2020). Effects of temperature, humidity, and diurnal temperature range on influenza incidence in a temperate region. Influenza Other Respi. Viruses 14, 11-18. doi: 10.1111 /irv.12682

Patel, N., Penkert, R. R., Jones, B. G., Sealy, R. E., Surman, S. L., Sun, Y., et al. (2019). Baseline serum vitamin A and D levels determine benefit of oral vitamin $\mathrm{A} \& \mathrm{D}$ supplements to humoral immune responses following pediatric influenza vaccination. Viruses 11:907. doi: 10.3390/v11100907

Peiris, J. S. M., Guan, Y., and Yuen, K. Y. (2004). Severe acute respiratory syndrome. Nat. Med. 10, S88-S97. doi: 10.1038/nm1143

Perlman, S., and Netland, J. (2009). Coronaviruses post-SARS: update on replication and pathogenesis. Nat. Rev. Microbiol. 7, 439-450. doi: $10.1038 /$ nrmicro2147

Phan, L. T., Nguyen, T. V., Luong, Q. C., Nguyen, T. V., Nguyen, H. T., Le, H. Q., et al. (2020). Importation and human-to-human transmission of a novel coronavirus in vietnam. N. Engl. J. Med. 382, 872-874. doi: 10.1056/NEJMc2001272

Phan, T. (2020a). Genetic diversity and evolution of SARS-CoV-2. Infect. Genet. Evol. 81:104260. doi: 10.1016/j.meegid.2020.104260

Phan, T. (2020b). Novel coronavirus: from discovery to clinical diagnostics. Infect. Genet. Evol. 79:104211. doi: 10.1016/j.meegid.2020.104211

Prasad, A. S. (2013). Discovery of human zinc deficiency: its impact on human health and disease. Adv. Nutr. 4, 176-190. doi: 10.3945/an.112.003210

Provinciali, M., Montenovo, A., Di Stefano, G., Colombo, M., Daghetta, L., Cairati, M., et al. (1998). Effect of zinc or zinc plus arginine supplementation on antibody titre and lymphocyte subsets after influenza vaccination in elderly subjects: a randomized controlled trial. Age Ageing 27, 715-722. doi: 10.1093/ageing/27.6.715

Qiu, R., Wei, X., Zhao, M., Zhong, C., Zhao, C., Hu, J., et al. (2020). Outcome reporting from protocols of clinical trials of coronavirus disease 2019 (COVID19): a review. medRxiv. doi: 10.1101/2020.03.04.20031401. [Epub ahead of print].

Raboud, J., Shigayeva, A., McGeer, A., Bontovics, E., Chapman, M., Gravel, D., et al. (2010). Risk factors for SARS transmission from patients requiring intubation: a multicentre investigation in Toronto, Canada. PLoS ONE 5:e10717. doi: 10.1371/journal.pone.0010717

Radonovich, L. J., Simberkoff, M. S., Bessesen, M. T., Brown, A. C., Cummings, D. A. T., Gaydos, C. A., et al. (2019). N95 respirators vs medical masks for preventing influenza among health care personnel: a randomized clinical trial. J. Am. Med. Assoc. 322, 824-833. doi: 10.1001/jama.2019.11645

Raj, V. S., Mou, H., Smits, S. L., Dekkers, D. H. W., Müller, M. A., Dijkman, R., et al. (2013). Dipeptidyl peptidase 4 is a functional receptor for the emerging human coronavirus-EMC. Nature 495, 251-254. doi: 10.1038/nature 12005

Raoult, D., Zumla, A., Locatelli, F., Ippolito, G., and Kroemer, G. (2020). Coronavirus infections: epidemiological, clinical and immunological features and hypotheses. Cell Stress 4, 66-75. doi: 10.15698/cst2020.04.216
Rayman, M. P. (2012). Selenium and human health. Lancet 379, 1256-1268. doi: 10.1016/S0140-6736(11)61452-9

Read, S. A., Obeid, S., Ahlenstiel, C., and Ahlenstiel, G. (2019). The role of zinc in antiviral immunity. Adv. Nutr. 10, 696-710. doi: 10.1093/advances/nmz013

Ren, L.-L., Wang, Y.-M., Wu, Z.-Q., Xiang, Z.-C., Guo, L., Xu, T., et al. (2020). Identification of a novel coronavirus causing severe pneumonia in human. Chin. Med. J. 133, 1015-1024. doi: 10.1097/cm9.0000000000000722

Richardson, P., Griffin, I., Tucker, C., Smith, D., Oechsle, O., Phelan, A., et al. (2020). Baricitinib as potential treatment for 2019-nCoV acute respiratory disease. Lancet 395, e30-e31. doi: 10.1016/S0140-6736(20)30304-4

Rossignol, J. F. (2016). Nitazoxanide, a new drug candidate for the treatment of middle east respiratory syndrome coronavirus. J. Infect. Public Health 9, 227-230. doi: 10.1016/j.jiph.2016.04.001

Rupp, J. C., Locatelli, M., Grieser, A., Ramos, A., Campbell, P. J., Yi, H., et al. (2017). Host cell copper transporters CTR1 and ATP7A are important for influenza A virus replication. Virol. J. 14, 1-12. doi: 10.1186/s12985-016-0671-7

Saitou, N., and Nei, M. (1987). The neighbor-joining method: a new method for reconstructing phylogenetic trees. Mol. Biol. Evol. 4, 406-425. doi: 10.1093/oxfordjournals.molbev.a040454

Scavone, C., Brusco, S., Bertini, M., Sportiello, L., Rafaniello, C., Zoccoli, A., et al. (2020). Current pharmacological treatments for COVID-19: what's next? Br. J. Pharmacol. doi: 10.1111/bph.15072. [Epub ahead of print].

Sciensano (2020). Interim Clinical Guidance for Patients Suspected of Confirmed With COVID-19. Belgium. Available online at: https://covid-19.sciensano.be/ sites/default/files/Covid19/COVID-19_InterimGuidelines_Treatment_ENG. pdf (accessed June 7, 2020).

Shang, L., Zhao, J., Hu, Y., Du, R., and Cao, B. (2020). On the use of corticosteroids for 2019-nCoV pneumonia. Lancet 395, 683-684. doi: 10.1016/S0140-6736(20)30361-5

Sheahan, T. P., Sims, A. C., Graham, R. L., Menachery, V. D., Gralinski, L. E., Case, J. B., et al. (2017). Broad-spectrum antiviral GS-5734 inhibits both epidemic and zoonotic coronaviruses. Sci. Transl. Med. 9:eaal3653. doi: 10.1126/scitranslmed.aal3653

Shen, C., Wang, Z., Zhao, F., Yang, Y., Li, J., Yuan, J., et al. (2020). Treatment of 5 critically III patients with COVID-19 with convalescent plasma. J. Am. Med. Assoc. 323, 1582-1589. doi: 10.1001/jama.2020.4783

Shiraki, K., and Daikoku, T. (2020). Favipiravir, an anti-influenza drug against life-threatening RNA virus infections. Pharmacol. Ther. 209:107512. doi: 10.1016/j.pharmthera.2020.107512

Siddiqui, F. Q., Ahmad, M. M., Kakar, F., Akhtar, S., and Dil, A. S. (2001). The role of vitamin A in enhancing humoral immunity produced by antirabies vaccine. East. Mediterr. Health J. 7, 799-804. Available online at: http://www.ncbi.nlm. nih.gov/pubmed/15332782 (accessed June 4, 2020).

Simmons, G., Reeves, J. D., Rennekamp, A. J., Amberg, S. M., Piefer, A. J., and Bates, P. (2004). Characterization of severe acute respiratory syndromeassociated coronavirus (SARS-CoV) spike glycoprotein-mediated viral entry. Proc. Natl. Acad. Sci. U.S.A. 101, 4240-4245. doi: 10.1073/pnas.0306446101

Sinha, N., and Balayla, G. (2020). Hydroxychloroquine and covid-19. Postgrad. Med. J. doi: 10.1136/postgradmedj-2020-137785. [Epub ahead of print].

Slater, H (2020). FDA Approves Phase III Clinical Trial of Tocilizumab for COVID-19 Pneumonia. Cancer Net. Available online at: https://www. cancernetwork.com/view/fda-approves-phase-iii-clinical-trial-tocilizumabcovid-19-pneumonia (accessed June 7, 2020).

Smith, J. D., MacDougall, C. C., Johnstone, J., Copes, R. A., Schwartz, B., and Garber, G. E. (2016). Effectiveness of N95 respirators versus surgical masks in protecting health care workers from acute respiratory infection: a systematic review and meta-analysis. CMAJ 188, 567-574. doi: 10.1503/cmaj.150835

Snijder, E. J., van der Meer, Y., Zevenhoven-Dobbe, J., Onderwater, J. J. M., van der Meulen, J., Koerten, H. K., et al. (2006). Ultrastructure and origin of membrane vesicles associated with the severe acute respiratory syndrome coronavirus replication complex. J. Virol. 80, 5927-5940. doi: 10.1128/jvi.02501-05

Stebbing, J., Phelan, A., Griffin, I., Tucker, C., Oechsle, O., Smith, D., et al. (2020). COVID-19: combining antiviral and anti-inflammatory treatments. Lancet Infect. Dis. 20, 400-402. doi: 10.1016/S1473-3099(20)30132-8

Stockman, L. J., Bellamy, R., and Garner, P. (2006). SARS: Systematic review of treatment effects. PLoS Med. 3, 1525-1531. doi: 10.1371/journal.pmed.0030343

Tang, F., Quan, Y., Xin, Z.-T., Wrammert, J., Ma, M.-J., Lv, H., et al. (2011). Lack of peripheral memory $\mathrm{B}$ cell responses in recovered patients with severe acute 
respiratory syndrome: a six-year follow-up study. J. Immunol. 186, 7264-7268. doi: 10.4049/jimmunol.0903490

Tang, N., Bai, H., Chen, X., Gong, J., Li, D., and Sun, Z. (2020). Anticoagulant treatment is associated with decreased mortality in severe coronavirus disease 2019 patients with coagulopathy. J. Thromb. Haemost. 18, 1094-1099. doi: $10.1111 /$ jth. 14817

Therapeutics Initiative (2020). Acetaminophen vs. NSAIDs During COVID19 Pandemic. Available online at: https://www.ti.ubc.ca/2020/03/18/ acetaminophen-vs-nsaids-during-covid-19-pandemic/ (accessed June 7, 2020).

To, K. K.-W., Tsang, O. T.-Y., Leung, W.-S., Tam, A. R., Wu, T.-C., Lung, D. C., et al. (2020). Temporal profiles of viral load in posterior oropharyngeal saliva samples and serum antibody responses during infection by SARSCoV-2: an observational cohort study. Lancet Infect. Dis. 20, P565-P574. doi: 10.1016/s1473-3099(20)30196-1

Tran, K., Cimon, K., Severn, M., Pessoa-Silva, C. L., and Conly, J. (2012). Aerosol generating procedures and risk of transmission of acute respiratory infections to healthcare workers: a systematic review. PLoS ONE 7:e35797. doi: 10.1371/journal.pone.0035797

Tu, X., Chong, W. P., Zhai, Y., Zhang, H., Zhang, F., Wang, S., et al. (2015). Functional polymorphisms of the CCL2 and MBL genes cumulatively increase susceptibility to severe acute respiratory syndrome coronavirus infection. J. Infect. 71, 101-109. doi: 10.1016/j.jinf.2015.03.006

Turnlund, J. R., Jacob, R. A., Keen, C. L., Strain, J. J., Kelley, D. S., Domek, J. M., et al. (2004). Long-term high copper intake: effects on indexes of copper status, antioxidant status, and immune function in young men. Am. J. Clin. Nutr. 79, 1037-1044. doi: 10.1093/ajcn/79.6.1037

Vincent, M. J., Bergeron, E., Benjannet, S., Erickson, B. R., Rollin, P. E., Ksiazek, T. G., et al. (2005). Chloroquine is a potent inhibitor of SARS coronavirus infection and spread. Virol. J. 2:69. doi: 10.1186/1743-422X-2-69

Wagstaff, K. M., Sivakumaran, H., Heaton, S. M., Harrich, D., and Jans, D. A. (2012). Ivermectin is a specific inhibitor of importin $\alpha / \beta$-mediated nuclear import able to inhibit replication of HIV-1 and dengue virus. Biochem. J. 443, 851-856. doi: 10.1042/BJ20120150

Wang, D., Hu, B., Hu, C., Zhu, F., Liu, X., Zhang, J., et al. (2020a). Clinical characteristics of 138 hospitalized patients with 2019 novel coronavirusinfected pneumonia in Wuhan, China. J. Am. Med. Assoc. 323, 1061-1069. doi: 10.1001/jama.2020.1585

Wang, H., Yang, P., Liu, K., Guo, F., Zhang, Y., Zhang, G., et al. (2008). SARS coronavirus entry into host cells through a novel clathrin- and caveolaeindependent endocytic pathway. Cell Res. 18, 290-301. doi: 10.1038/cr.2008.15

Wang, M., Cao, R., Zhang, L., Yang, X., Liu, J., Xu, M., et al. (2020b). Remdesivir and chloroquine effectively inhibit the recently emerged novel coronavirus (2019-nCoV) in vitro. Cell Res. 30, 269-271. doi: 10.1038/s41422-020-0282-0

Wang, M., Jiang, A., Gong, L., Luo, L., Guo, W., Li, C., et al. (2020c). Temperature significant change COVID-19 transmission in 429 cities. medRxiv. doi: 10.1101/2020.02.22.20025791. [Epub ahead of print].

Wang, S. F., Chen, K. H., Chen, M., Li, W. Y., Chen, Y. J., Tsao, C. H., et al. (2011). Human-leukocyte antigen class I CW 1502 and class II DR 0301 genotypes are associated with resistance to severe acute respiratory syndrome (SARS) infection. Viral Immunol. 24, 421-426. doi: 10.1089/vim.2011.0024

Wang, W., Tang, J., and Wei, F. (2020d). Updated understanding of the outbreak of 2019 novel coronavirus (2019-nCoV) in Wuhan, China. J. Med. Virol. 92, 441-447. doi: 10.1002/jmv.25689

Wang, Y., Cui, R., Li, G., Gao, Q., Yuan, S., Altmeyer, R., et al. (2016). Teicoplanin inhibits Ebola pseudovirus infection in cell culture. Antiviral Res. 125, 1-7. doi: 10.1016/j.antiviral.2015.11.003

Warren, T. K., Jordan, R., Lo, M. K., Ray, A. S., Mackman, R. L., Soloveva, V., et al. (2016). Therapeutic efficacy of the small molecule GS-5734 against Ebola virus in rhesus monkeys. Nature 531, 381-385. doi: 10.1038/nature 17180

Weiss, S. R., and Leibowitz, J. L. (2011). “Coronavirus pathogenesis," in Advances in Virus Research, eds M. Kielian, T. C. Mettenleiter, and M. J. Roossinck (Academic Press), 85-164. doi: 10.1016/B978-0-12-385885-6.00009-2. Available online at: https://www.sciencedirect.com/bookseries/advances-invirus-research

WHO (2020a). Coronavirus Disease (COVID-19) Technical Guidance: Laboratory Testing for 2019-nCoV in Humans. Available online at: https://www.who.int/ emergencies/diseases/novel-coronavirus-2019/technical-guidance/laboratoryguidance (accessed June 7, 2020).

WHO (2020b). Advice on the Use of Masks in the Context of COVID-19. Available online at: https://apps.who.int/iris/rest/bitstreams/1274280/retrieve (accessed June 7,2020$)$.

WHO (2020c). Landscape Analysis of Therapeutics as 21st March 2020. Available online at: https://www.who.int/blueprint/priority-diseases/key-action/Table of_therapeutics_Appendix_17022020.pdf?ua=1 (accessed June 7, 2020).

WHO (2020d). Novel Coronavirus - China. Available online at: https://www.who. int/csr/don/12-january-2020-novel-coronavirus-china/en/ (accessed June 7 , 2020).

WHO (2020e). Report of the WHO-China Joint Mission on Coronavirus Disease 2019 (COVID-19). Available online at: http://www.who.int/docs/defaultsource/coronaviruse/who-china-joint-mission-on-covid-19-final-report.pdf (accessed June 7, 2020).

Williams, A. E., and Chambers, R. C. (2014). The mercurial nature of neutrophils: still an enigma in ARDS? Am. J. Physiol. 306, L217-L30. doi: 10.1152/ajplung.00311.2013

Wösten-van Asperen, R. M., Bos, A. P., Bem, R. A., Dierdorp, B. S., Dekker, T., van Goor, H., et al. (2013). Imbalance between pulmonary angiotensinconverting enzyme and angiotensin-converting enzyme 2 activity in acute respiratory distress syndrome. Pediatr. Crit. Care Med. 14, e438-e441. doi: 10.1097/PCC.0b013e3182a55735

Wu, C., Chen, X., Cai, Y., Xia, J., Zhou, X., Xu, S., et al. (2020a). Risk factors associated with acute respiratory distress syndrome and death in patients with coronavirus disease 2019 pneumonia in Wuhan, China. JAMA Intern. Med. 13:e200994. doi: 10.1001/jamainternmed.2020.0994

Wu, F., Zhao, S., Yu, B., Chen, Y. M., Wang, W., Song, Z. G., et al. (2020b). A new coronavirus associated with human respiratory disease in China. Nature 579, 265-269. doi: 10.1038/s41586-020-2008-3

Xinhua News Agency (2020). Favipiravir Shows Good Clinical Efficacy in Treating COVID-19: Official. Available online at: http://www.xinhuanet.com/english/ 2020-03/17/c_138887971.htm (accessed June 7, 2020).

Xu, Z., Shi, L., Wang, Y., Zhang, J., Huang, L., Zhang, C., et al. (2020). Pathological findings of COVID-19 associated with acute respiratory distress syndrome. Lancet Respir. Med. 8, 420-422. doi: 10.1016/S2213-2600(20)30076-X

Yan, Y., Zou, Z., Sun, Y., Li, X., Xu, K. F., Wei, Y., et al. (2013). Anti-malaria drug chloroquine is highly effective in treating avian influenza A H5N1 virus infection in an animal model. Cell Res. 23, 300-302. doi: 10.1038/cr.2012.165

Yang, S. N. Y., Atkinson, S. C., Wang, C., Lee, A., Bogoyevitch, M. A., Borg, N. A., et al. (2020a). The broad spectrum antiviral ivermectin targets the host nuclear transport importin $\alpha / \beta 1$ heterodimer. Antiviral Res. 177:104760. doi: 10.1016/j.antiviral.2020.104760

Yang, X., Yu, Y., Xu, J., Shu, H., Xia, J., Liu, H., et al. (2020b). Clinical course and outcomes of critically ill patients with SARS-CoV-2 pneumonia in Wuhan, China: a single-centered, retrospective, observational study. Lancet Respir. Med. 8, P475-P481. doi: 10.1016/S2213-2600(20)30079-5

Yang, Y., Zhang, L., Geng, H., Deng, Y., Huang, B., Guo, Y., et al. (2013). The structural and accessory proteins M, ORF $4 \mathrm{a}$, ORF $4 \mathrm{~b}$, and ORF 5 of middle east respiratory syndrome coronavirus (MERS-CoV) are potent interferon antagonists. Protein Cell 4, 951-961. doi: 10.1007/s13238-013-3096-8

Yao, X., Ye, F., Zhang, M., Cui, C., Huang, B., Niu, P., et al. (2020). In vitro antiviral activity and projection of optimized dosing design of hydroxychloroquine for the treatment of severe acute respiratory syndrome coronavirus 2 (SARS-CoV2). Clin. Infect. Dis. 9:eciaa237. doi: 10.1093/cid/ciaa237

Yee, J., Unger, L., Zadravecz, F., Cariello, P., Seibert, A., Johnson, M. A., et al. (2020). Novel coronavirus 2019 (COVID-19): emergence and implications for emergency care. J. Am. Coll. Emerg. Physicians Open 1, 63-69. doi: 10.1002/emp2.12034

Yeo, C., Kaushal, S., and Yeo, D. (2020). Enteric involvement of coronaviruses: is faecal-oral transmission of SARS-CoV-2 possible? Lancet Gastroenterol. Hepatol. 5, 335-337. doi: 10.1016/S2468-1253(20)30048-0

Yu, F., Du, L., Ojcius, D. M., Pan, C., and Jiang, S. (2020). Measures for diagnosing and treating infections by a novel coronavirus responsible for a pneumonia outbreak originating in Wuhan, China. Microbes Infect. 22, 74-79. doi: 10.1016/j.micinf.2020.01.003

Yuan, F. F., Tanner, J., Chan, P. K. S., Biffin, S., Dyer, W. B., Geczy, A. F., et al. (2005). Influence of FcgammaRIIA and MBL polymorphisms 
on severe acute respiratory syndrome. Tissue Antigens 66, 291-296. doi: 10.1111/j.1399-0039.2005.00476.x

Zdrenghea, M. T., Makrinioti, H., Bagacean, C., Bush, A., Johnston, S. L., and Stanciu, L. A. (2017). Vitamin D modulation of innate immune responses to respiratory viral infections. Rev. Med. Virol. 27:e1909. doi: 10.1002/rmv.1909

Zhang, C., Huang, S., Zheng, F., and Dai, Y. (2020a). Controversial treatments: an updated understanding of the coronavirus disease 2019. J. Med. Virol. doi: 10.1002/jmv.25788. [Epub ahead of print].

Zhang, H., Kang, Z., Gong, H., Xu, D., Wang, J., Li, Z., et al. (2020b). The digestive system is a potential route of 2019-nCov infection: a bioinformatics analysis based on single-cell transcriptomes. bioRxiv. doi: 10.1101/2020.01.30.927806. [Epub ahead of print].

Zhao, J., Li, K., Wohlford-Lenane, C., Agnihothram, S. S., Fett, C., Zhao, J., et al. (2014). Rapid generation of a mouse model for Middle East respiratory syndrome. Proc. Natl. Acad. Sci. U.S.A. 111, 4970-4975. doi: $10.1073 /$ pnas.1323279111

Zhao, S., Lin, Q., Ran, J., Musa, S. S., Yang, G., Wang, W., et al. (2020). Preliminary estimation of the basic reproduction number of novel coronavirus (2019$\mathrm{nCoV}$ ) in China, from 2019 to 2020: a data-driven analysis in the early phase of the outbreak. Int. J. Infect. Dis. 92, 214-217. doi: 10.1016/j.ijid.2020.01.050

Zhou, F., Yu, T., Du, R., Fan, G., Liu, Y., Liu, Z., et al. (2020). Clinical course and risk factors for mortality of adult inpatients with COVID-19 in Wuhan, China: a retrospective cohort study. Lancet 395, 1054-1062. doi: 10.1016/S0140-6736(20)30566-3
Zhou, N., Pan, T., Zhang, J., Li, Q., Zhang, X., Bai, C., et al. (2016). Glycopeptide antibiotics potently inhibit cathepsin $\mathrm{l}$ in the late endosome/lysosome and block the entry of ebola virus, middle east respiratory syndrome coronavirus (MERS$\mathrm{CoV}$ ), and severe acute respiratory syndrome coronavirus (SARS-CoV). J. Biol. Chem. 291, 9218-9232. doi: 10.1074/jbc.M116.716100

Zhou, Y., Vedantham, P., Lu, K., Agudelo, J., Carrion, R., Nunneley, J. W., et al. (2015). Protease inhibitors targeting coronavirus and filovirus entry. Antiviral Res. 116, 76-84. doi: 10.1016/j.antiviral.2015.01.011

Zumla, A., Chan, J. F. W., Azhar, E. I., Hui, D. S. C., and Yuen, K. Y. (2016). Coronaviruses-drug discovery and therapeutic options. Nat. Rev. Drug Discov. 15, 327-347. doi: 10.1038/nrd. 2015.37

Conflict of Interest: The authors declare that the research was conducted in the absence of any commercial or financial relationships that could be construed as a potential conflict of interest.

Copyright (C) 2020 Kabir, Uddin, Hossain, Abdulhakim, Alam, Ashraf, Bungau, BinJumah, Abdel-Daim and Aleya. This is an open-access article distributed under the terms of the Creative Commons Attribution License (CC BY). The use, distribution or reproduction in other forums is permitted, provided the original author(s) and the copyright owner(s) are credited and that the original publication in this journal is cited, in accordance with accepted academic practice. No use, distribution or reproduction is permitted which does not comply with these terms. 